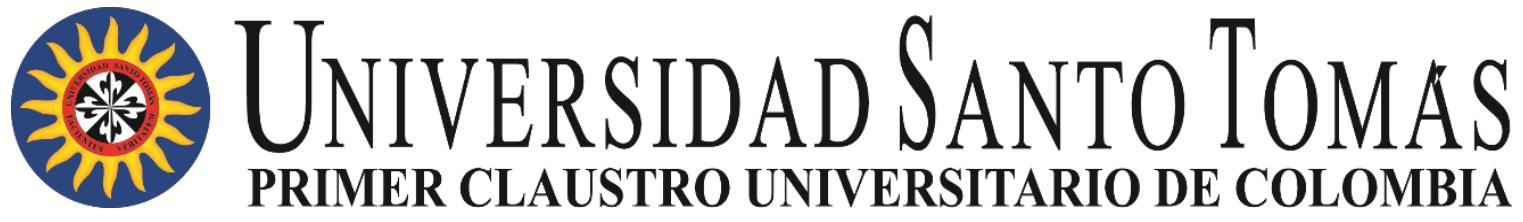

PROYECTO DE INVESTIGACIÓN ADMINISTRACIÓN DE EMPRESAS

ANÁLISIS ESTRATÉGICO SECTORIAL DEL SECTOR DE LOS CENTROS COMERCIALES EN LA CIUDAD DE BOGOTÁ

\author{
DIRECTOR \\ ALCIBIADES ALIRIO CESPEDES GIL \\ AUXILIAR DE INVESTIGACIÓN \\ GERALDINE SOFÍA MARTÍNEZ QUINTERO
}

Bogotá D.C, Julio de 2019 


\title{
ANÁLISIS ESTRATÉGICO SECTORIAL DEL SECTOR DE LOS CENTROS COMERCIALES EN LA CIUDAD DE BOGOTÁ
}

\author{
Resumen \\ La investigación propone realizar un análisis sectorial estratégico del subsector de los centros comerciales de la ciudad \\ de Bogotá, bajo una óptica prospectiva que incluye el análisis de elementos como nivel de hacinamiento cualitativo y \\ cuantitativo, asimetrías financieras, erosión estratégica y de la productividad, crecimiento potencial sostenible entre otras \\ variables con el objeto de concluir respecto a la tendencia estratégica sectorial futura y proponer algunas acciones que \\ eviten la morbilidad del sector.
}

\begin{abstract}
The research proposes to carry out a strategic sector analysis of the sub-sector of the shopping centers of the city of Bogotá, under a prospective perspective that includes the analysis of elements such as qualitative and quantitative level of overcrowding, financial asymmetries, strategic erosion and productivity, potential growth sustainable among other variables in order to conclude regarding the future strategic sector trend and propose some actions that avoid the morbility of the sector.
\end{abstract}

Palabras clave (máximo 5): estrategia, productividad, competitividad, perdurabilidad

Keywords (maximum 5): strategy, productivity, competitiveness, durability

JEL Cod: L20; L22; L80 


\section{Introducción}

La tendencia a la imitación siempre ha estado presente en el comportamiento estratégico agregado de un sector y en términos generales es quizás el principal factor que reduce su competitividad. El fenómeno del isomorfismo que más adelante provoca convergencia e imitación, debe ser monitoreado de forma permanente por los estrategas de las compañías con el objeto de determinar las señales tempranas de alerta y evitar caer en una profunda crisis de innovación empresarial y sectorial que, debido al impacto en la pobre generación de rendimientos financieros lleva indefectiblemente a la muerte empresarial.

Por esta razón, tiene un especial interés el análisis del sector de los centros comerciales, que en los últimos años ha venido creciendo con una oferta que parece variada pero que amerita un estudio estratégico detallado con el fin de determinar su grado de imitación y por tanto las acciones futuras posibles para evitar que este caiga en un ciclo de contracción. En este orden de ideas la pregunta de investigación que se plantea es:

¿Cuál es el comportamiento estratégico sectorial del sector de centros comerciales en la ciudad de Bogotá?

El análisis estratégico sectorial, es “condición necesaria aunque insuficiente para emprender la batalla de la perdurabilidad con crecimiento rentable“ (Puerta, 2008, págs. 27,28). El estratega por lo tanto tiene como una de sus principales responsabilidades la correcta lectura e interpretación de su entorno, el análisis prospectivo del futuro empresarial y las respectivas propuestas de crecimiento perdurable de la empresa que lidera. 
La observación sistémica de toda esta compleja red de interacciones entre clientes, proveedores, productos y rivales a través del uso de herramientas no convencionales (esto es modelos no lineales) le permitirán encontrar al director empresarial un detalle importante sobre su empresa, el entorno en el que está envuelta y ante todo los posibles derroteros a seguir. Es por ello que con esta investigación aplicada en los Centros comerciales de la ciudad de Bogotá se pretende hacer un análisis de las diversas variables e interacciones que les influyen, con el fin de tener una mayor comprensión del entorno que les rodea y de esta manera identificar nuevas oportunidades para su mejoramiento. Los sectores estratégicos, en este caso el integrado por de los Centros comerciales, son primero que todos sistemas dinámicos, vivos y complejos, que requieren de modelos mentales diferentes para ser analizados al igual que construcciones prospectivas que lejos de intentar reducir la incertidumbre busquen comprenderla en el marco de un sector económico específico. Finalmente el resultado del análisis deberá ser una comprensión medianamente profunda de la dinámica interna del sector estudiado como condición de obligatorio recorrido en la búsqueda de la perdurabilidad empresarial.

\section{Marco teórico}

En las décadas de los 70 y 80, Michael Porter desarrolló varios elementos básicos que modelaron los desarrollos de estrategia competitiva en los años posteriores. El primero tiene que ver con la manera en que un mercado es moldeado a través del comportamiento de cinco fuerzas que interactúan permanentemente buscando establecer poderes de 
negociación relativos superiores. Tales fuerzas son: rivalidad entre competidores, poder de negociación con proveedores, poder de negociación con clientes, amenaza de entrada de nuevos competidores y amenaza de ingreso de productos sustitutos (Porter, 1979). Posteriormente, Porter (1980) incluye en su teoría los conceptos de análisis de la industria y competidores, sofisticando los análisis estratégicos de entorno así como las estrategias, todo dentro del marco de la rivalidad estratégica. Más adelante, Porter (1985) hace un análisis detallado de la cadena de valor y como sus actividades son las que crean las diferencias competitivas que le van a permitir a una empresa desarrollar diferencias en el mercado.

El estudio del comportamiento sectorial ha involucrado investigaciones desde las perspectivas del mercadeo, la sociología y la economía empresarial buscando ante todo reducir la posibilidad de imitación de las propuestas de valor que, según autores como Nattermann (1997), Kim \& Mauborgne (2004) y Restrepo Puerta et al. (2008), restringe la perdurabilidad de una empresa y suprime el valor económico agregado que existe dentro de un sector económico. Kim \& Mauborgne (2004) desarrollaron el concepto de "océanos azules" donde establecen un paralelo entre la tranquilidad que representa un océano azul equivalente a mercados completamente libres de imitación, frente a océanos rojos con alta rivalidad. Bajo esta nueva óptica, tanto Kim \& Mauborgne (2005a; 2005b) como Burke et al. $(2009,2010)$ proponen a los estrategas buscar sistemáticamente océanos azules para sus empresas de tal manera que se alejen de la rivalización directa con sus competidores y tengan un alto enfoque hacia la innovación. 
Otras corrientes de pensamiento, desarrollan la idea del proceso de imitación como una estrategia válida para defender la posición de una compañía dentro de su mercado (Pidal González, 2008). Esto es posible si además se complementa la estrategia con procesos de perfeccionamiento del producto o servicio ofrecido entregando al mercado nuevos atributos que no eran claramente percibidos dentro del producto original.

Hax \& Majluf (1993) desarrollaron un modelo de proceso estratégico que parte del análisis de los estados financieros de la corporación para determinar su posición estratégica dentro de la denominada matriz direccional. El resultado del estudio de dicha interacción determina el grado de agresividad o defensa que debe adquirir una compañía en función de la posición determinada en la matriz.

Nattermann (1997) estudió el fenómeno del hacinamiento y la erosión de los beneficios financieros de un sector estratégico como una de las respuestas implícitas a varios factores como el tamaño de las barreras de entrada de un sector, la sofisticación tecnológica, los recursos inimitables, el equilibrio económico de la oferta y la demanda y las maniobras estratégicas, entre otros. La convergencia estratégica es el fenómeno a través del cual las empresas que están involucradas en la competencia por los clientes de un mercado hacen reflexiones estratégicas similares (Restrepo Puerta \& Rivera Rodríguez, 2005). Esto es, los modelos mentales construidos a largo de los años por las empresas se han hecho tan parecidos, que las respuestas que dan los rivales del sector se parecen cada vez más.

Restrepo Puerta \& Rivera Rodríguez (2008) diseñaron un modelo cuantitativo de análisis del nivel de hacinamiento basado en indicadores financieros que permite determinar la llamada maduración del mercado o su nivel de hacinamiento, la asimetría entre empresas 
o sectores, el grado de concentración de los resultados financieros y las empresas o sectores con desempeño superior.

Tanto Prahalad \& Hammel (1994) como Prahalad \& Hart (2002) se cuestionan respecto a los modelos estratégicos corporativos ortodoxos y la rivalidad competitiva ya exacerbada por dichas estrategias y plantean una nueva aproximación a mercados no abordados con rupturas de los modelos estratégicos hasta ahora planteados. El nuevo modelo se fundamenta en la consideración de que la base de la pirámide social (la población con más bajos recursos económicos en el mundo) puede llegar a ser un gran mercado para las multinacionales y simultáneamente un nuevo paradigma socioeconómico.

En aras de comprender el Sectorial es necesario partir del enfoque general de donde se deriva, es decir, intentar una aproximación global de algunos conceptos que sirven como base de mercado para explicar sus raíces. Es por esta razón que se debe abordar el concepto de sector económico para ubicarse dentro de los límites espacio temporales de nuestra investigación, según el Departamento Nacional de Planeación (2000) (Banrepcultural) la actividad económica del país está dividida en partes, cuyos elementos poseen características, particularidades similares, que los hacen una unidad y a su vez las diferencian de otros grupos; su división y clasificación se efectúa partiendo de los procesos productivos que al interior de ellos se realizan.

Los sectores económicos a su vez contienen subdivisiones denominadas sectores estratégicos, los cuales se encuentran dentro de la clasificación CIIU del país. En los subsectores se encuentran aquellas empresas que son competidores directos ya que su 
desarrollo se limita y es afectado por las mismas variables (proveedores, compradores, bienes sustitutos y nivel de rivalidad).

\subsection{Rivalidad Empresarial}

La rivalidad entre las empresas, concepto desarrollado por Michael Porter dentro de sus cinco fuerzas del mercado (Porter, 1979), se puede definir como la disputa entre las empresas de un mismo sector económico, para posicionarse por encima de sus pares, y así adquirir una porción significativa del mercado utilizando diferentes tácticas como la disminución de precios, mejora o creación de productos, adquisiciones, etc.; situación que marca al interior de la empresa las necesidades de innovación para hacer frente a las estrategias de los competidores.

El nivel de rivalidad que se presente entre las empresas se intensifica en la medida en que se evidencie una mayor cantidad de los siguientes factores dentro del mercado:

a) Un gran número de competidores dentro del mercado con un fuerte musculo financiero.

b) Bajo crecimiento del mercado el cual genera una mayor lucha entre los competidores por una pequeña porción de este.

c) Elevados costos fijos.

d) Poca diversificación.

e) Incrementos de la capacidad de producción dentro de una economía de escala.

f) Diversos competidores (nacionales e internacionales).

g) Altas barreras arancelarias. 


\subsection{Isomorfismo}

Para comprender los diferentes fenómenos que enfrentan y afectan a las empresas, es indispensable saber que las empresas expresan, se desarrollan y evolucionan de acuerdo a la influencia generada por una persona o por un grupo de personas, a este hecho se le conoce como comportamiento laboral.

Se dice que las personas como entes pensantes, son conscientes que cuentan con un cerebro y lo reconocen como el centro de mando de todas las habilidades cognitivas, sin embargo, hoy en día está comprobado que dentro del cráneo se cuenta con "tres cerebros" conocidos como el cerebro básico reptiliano, el cerebro límbico mamífero y el cerebro humano neocortex.

¿Pero qué tiene que ver la clasificación de nuestro cerebro con el funcionamiento de las empresas?, sucede que en el cerebro conocido como el cerebro límbico, se cuenta con tres respuestas heredadas de la evolución propia del hombre, que aunque moderemos, siempre están presentes en nuestro actuar y se reflejan en cada acción o trabajo realizado por los seres humanos en su interacción con otros, estas tres respuestas límbicas son la parálisis, la huida y la lucha (Karlins, 2008).

El fenómeno conocido como Isomorfismo es una forma de expresión que ocurre en la respuesta límbica de la lucha, y se refiere a la imitación del comportamiento y estructura de dos seres, que buscan ser lo más parecidos posibles frente a su entorno. El nacimiento de este comportamiento ocurre cuando un ser humano imita las actitudes de otro ser 
humano o de un grupo social para ser parte de él y ser aceptado sin hacer uso consciente de la razón.

Este comportamiento se extiende a las empresas, que en su necesidad de lucha por el posicionamiento establecen normalmente políticas y estrategias basadas en la capacidad de imitar o copiar comportamientos exitosos de sus competidores y adaptarlos como parte del comportamiento propio y nativo de ellas mismas.

Cuando se revisa el isomorfismo con base en la sociología institucional, el cual busca explicar la tendencia de las empresas a imitarse en pro de ser aceptadas en el mercado de forma natural, apoyadas en el legado límbico de los directivos que guiados bajo la necesidad de la lucha organizacional, concepto que tiene como objetivo la explicación del fenómeno de la imitación; se genera el planteamiento de tres posibles orígenes, el isomorfismo coercitivo que obedece a la necesidad de la empresa para cumplir con estándares y procedimientos, el isomorfismo normativo que no es otra cosa diferente a la influencia de la experiencia profesional que homogeniza los estándares de conocimiento compartidos entre el personal que participa en las estructuras organizacionales, y por último el isomorfismo mimético o imitación de las prácticas exitosas del sector donde participa como jugador la empresa (DiMaggio \& Powell, 1983).

En el imaginario colectivo, que es un multiplicador del incremento del fenómeno del isomorfismo, se entiende como la imitación de la estrategia usada por una empresa para hacer de un proceso, servicio o producto un éxito, ya que al copiar esta estrategia o comportamiento se piensa que el mismo debe desencadenar un resultado de éxito parecido 
al inicialmente analizado. Sin embargo, este hecho lo único que desencadena es una convergencia estratégica en los sectores económicos.

Existen posturas adversas sobre el isomorfismo, a pesar de tener repercusiones negativas existen corrientes que defienden la imitación como estrategia de negocio. En estos planteamientos se destaca la posición de que la imitación es el acelerador para desarrollar nuevos productos, de tal manera que, también se encarga de incentivar y fomentar la innovación. Las empresas que imitan disminuyen el riesgo de incertidumbres comparadas con las empresas pioneras, dado esto se cuenta con mayor seguridad al éxito, logrando permanencia estable y sin mayores contratiempos.

También, es necesario plantear que la mayoría de las reflexiones que se hacen sobre estrategia invitan a interpretar el entorno como un paso necesario hacia la comprensión de la realidad que rodea a la empresa (Rodriguez H. A., 2004). Repasando las diferentes corrientes de pensamiento usualmente reconocidas, se nota una inclinación hacia utilizar panoplias de instrumentos o herramientas orientadas a tal fin. Esto ha permitido a los estrategas y analistas sectoriales comprender, cada vez mejor, lo que sucede más allá de los límites de la organización. Sin duda, reflexionar sobre el medio que rodea a la empresa es un ejercicio interesante, contentivo de limitaciones, pero abundante en alternativas interpretativas, y tratar de captar la complejidad sobre lo que ocurre en los sectores, lo que se ha convertido en tema de investigación para una gran variedad de instituciones alrededor del mundo, en especial para la academia. 
La realidad es que para que una empresa sea perdurable en el tiempo debe ejercer una fuerte planeación, lograr una ventaja competitiva real, la cual sea difícilmente imitable, y generar valor a sus clientes.

Mencionando el tema de ventaja competitiva sostenible, para la empresa existen dos ventajas alcanzables, la primera es la percepción exclusiva y la segunda la ventaja de costo más bajo (Puerta, 2004). En la ventaja de percepción exclusiva, la empresa busca el reconocimiento del consumidor, por lo cual este lo recompensa pagando mayores precios, su diferenciador es inigualable y su cadena de valor es difícilmente imitable, este tipo de ventaja genera clientes leales que hacen un portavoz de la marca para el consumo de servicios o productos. En la ventaja de costo más bajo, su objetivo es que los contrincantes identifiquen la empresa como el jugador con los mejores precios, la empresa debe tener una cultura orientada a la reducción de todos los costos en cada uno de sus procesos, una cultura organizacional orientada al ahorro.

Una cultura empresarial es el supuesto de la coordinación de los aspectos tanto sociales como culturales, es decir, la conexión entre sus formas establecidas de relación o nexos sociales, como de las interpretaciones subjetivas y actuaciones concretas en estas estructuras desarrolladas.

Debido a la velocidad del cambio en la actualidad, existe una mutación constante, la cual se está convirtiendo en un elemento consustancial a las culturas empresariales. La adaptabilidad es la respuesta de las organizaciones, claramente no respondiendo todas con la misma intensidad y potencia. (Caneda, DIRECCIÓN ESTRATÉGICA DE LA EMPRESA, 2015). 
Para dar respuesta a la necesidad de supervivencia de las empresas y afrontar los diferentes fenómenos o enfermedades que deterioran los sectores e incrementan las tasas de mortalidad empresarial, se plantean tres elementos necesarios para favorecer la adaptación y el crecimiento empresariales, la primera es una capacidad transformada en actitud, conocida como la creatividad empresarial, la segunda es la forma de actuar para perseverar en el entorno, también llamada como innovación organizacional, y por último una estructura interna que involucre las dos anteriores, a esto se le denomina arquitectura organizativa innovadora. La creatividad empresarial es la habilidad que permite modificar las limitaciones autoimpuestas que tiene como objetivo la producción de ideas nuevas y valiosas tanto para la propia organización como para el negocio. En definitiva, supone no anclarse sólo en la producción basada en el ingenio o la ocurrencia para centrarse en el fomento de las capacidades de creación propias del ser humano con una vertiente netamente práctica, una vez resaltada la importancia que la creatividad tiene como factor de competitividad y supervivencia, se necesita su puesta en valor, su aplicación práctica en definitiva y esa es precisamente la función de la innovación.

Sobre el tema de innovación, Arie de Geus, antiguo vicepresidente de Planificación Estratégica de Shell y actual gurú de éxito, plantea que "la única ventaja competitiva verdaderamente sostenible es la habilidad para aprender más rápido que tus competidores”, no sólo es la necesidad de ser distintas que tienen las empresas para ser apreciadas por el público objetivo, sino que está también la necesidad de responder a sus necesidades a través de la mayor velocidad de presentación en los mercados. 
En resumen, la innovación es la habilidad de transformar la creatividad en resultados tangibles y que aporten a la cifra de negocio así como a la cuenta de resultados, por último la arquitectura organizativa es la forma de repartir el trabajo y las responsabilidades entre los diferentes individuos que forman parte de las organizaciones, en especial las empresariales, con el fin de conseguir un objetivo común último, esto es, cómo organizarse para lograr los resultados empresariales marcados por la estrategia. Es, en resumen, la manera de estructurar las relaciones, plasmada habitualmente en un diseño gráfico denominado comúnmente organigrama. (Caneda, Dirección Estratégica Innovadora, 2010).

\subsection{Convergencia estratégica y erosión.}

Como se mencionó anteriormente, la convergencia estratégica es el resultado del isomorfismo presente en los actores dentro del mercado, ya que esta no es más que el desarrollo de estrategias similares entre las diferentes empresas que componen o pertenecen a un sector estratégico específico, la cual trae como consecuencia una erosión en la rentabilidad de los sectores estratégicos.

La convergencia estratégica se puede presentar en las empresas ya sea bien por el uso de los canales de distribución similares o por satisfacer de la misma manera las necesidades del mercado, la constante imitación entre las compañías genera una guerra de precios en el sector al cual pertenecen, lo que a su vez lleva a este a un futuro hacinamiento sectorial. 


\subsection{Hacinamiento sectorial}

El hacinamiento sectorial genera la disminución de la tasa media de rentabilidad de un sector y se puede evidenciar en el mercado gracias a las similitudes en las acciones y estrategias que realizan las empresas de dicho sector. Para poder realizar este análisis se debe tener presente el siguiente algoritmo expresado en el libro "Análisis Estructural de Sectores Estratégicos":

\section{Gráfico 1. Análisis de hacinamiento}

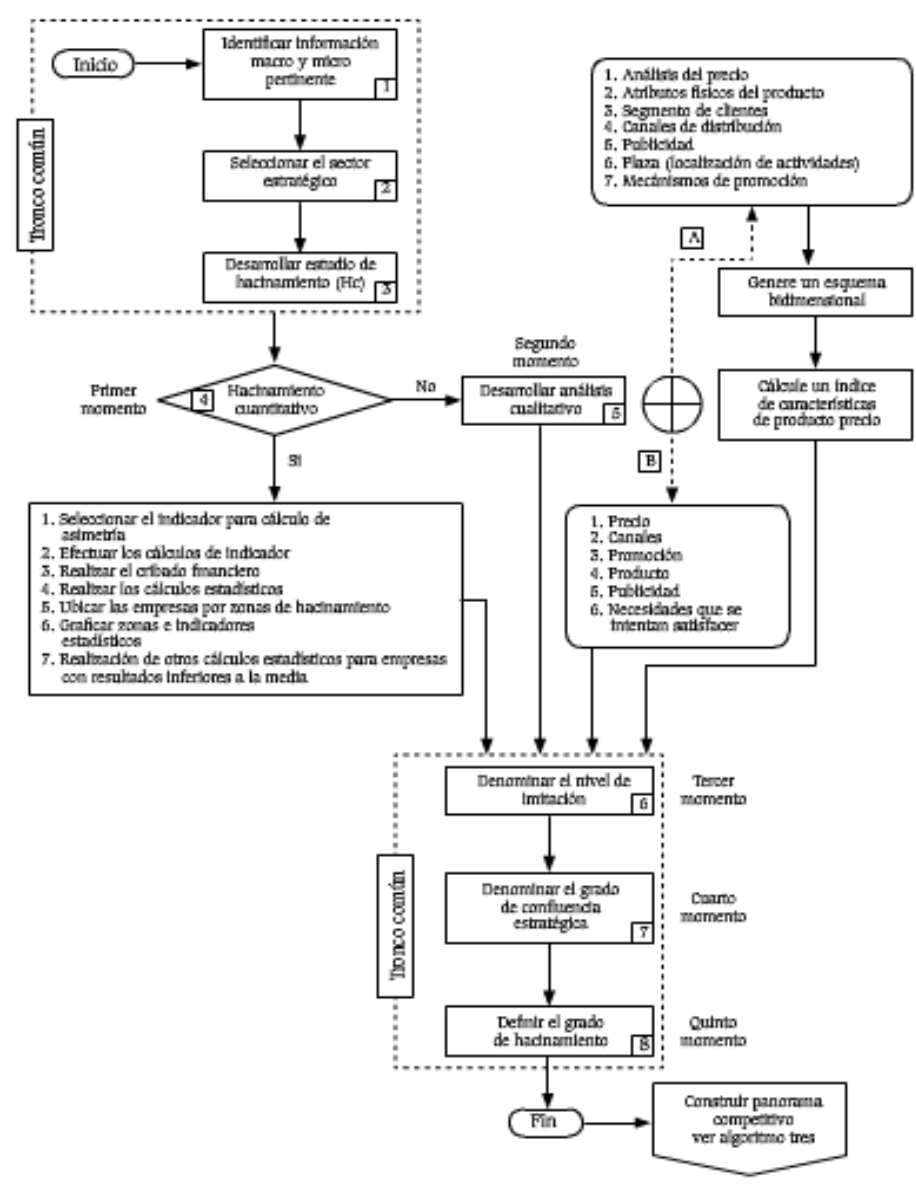

Fuente: Libro "Análisis Estructural de Sectores Estratégicos” 


\subsubsection{Cuantitativo}

Para poder realizar un análisis completo del hacinamiento en un sector económico, se debe hacer una medición cuantitativa de este, la cual debe tener como base una valoración financiera donde se realiza un análisis estadístico de la información con elementos como la kurtosis, asimetría, diagramas de dispersión y el coeficiente de variación. Para lograrlo se deben realizar los siguientes pasos expuestos por Hugo Alberto Rivera Rodriguez en el documento "El hacinamiento, la enfermedad que los estrategas deben curar":

a) Selección del indicador para el cálculo de la asimetría: Se hace necesario el uso de un indicador cuantitativo para determinar si existe o no hacinamiento cuantitativo, este indicador no necesariamente debe ser financiero pero debe permitir evaluar el comportamiento del sector estratégico.

b) Efectuar los cálculos del indicador: cuando se cuenta con el indicador que ilustra el panorama del sector, se aplica los cálculos correspondientes a cada uno de las empresas que existen en el ecosistema del sector estratégico, el lapso de tiempo de los datos tomados no debe ser inferior a 5 años para cada una de ellas.

c) Cálculos estadísticos:

i. Cálculo y análisis del coeficiente de variación, el objetivo es identificar las empresas que se encuentran debajo de la media del indicador seleccionado 
ii. Calculo de la desviación estándar, se dice que si al menos el $85 \%$ de las empresas del sector estratégico analizadas se encuentran en la media aritmética los resultados financieros son homogéneos, lo cual indica alto desempeño de algunas pocas empresas.

iii. Análisis de morbilidad y mortalidad, la morbilidad es la enfermedad que describe a empresas con incapacidad de obtener resultados superiores a la media del sector o incapacidad de obtener utilidad.

d) Ubicación de las empresas por zonas de hacinamiento:

i. Zona 1, empresas cuyo indicador se encuentra por encima del tercer cuartil

ii. Empresas ubicadas entre la media y el tercer cuartil

iii. Empresas ubicadas entre la mediana y la media

iv. Empresas ubicadas por debajo de la mediana o la media

v. Empresas con resultados negativos del indicador seleccionado

e) Generación de gráficas de las zonas e indicadores estadísticos: mediante los gráficos se espera mejorar la interpretación del analista para lograr conclusiones acertadas.

f) Análisis de datos: las empresas cuyo desempeño se encuentre por debajo del percentil 75 es necesario analizarlas y estudiarlas por separado. 
Gráfico 2. Zonas de hacinamiento

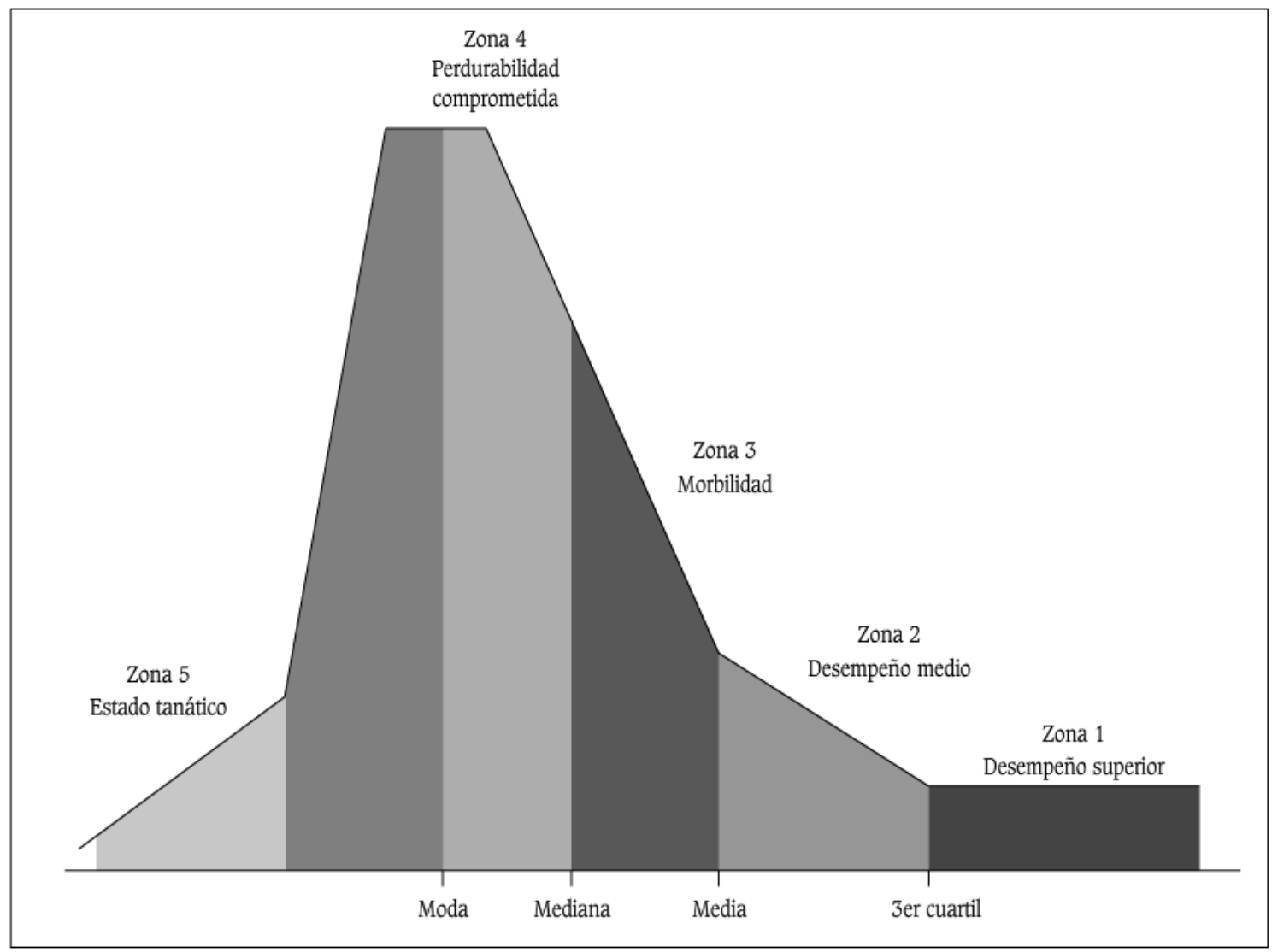

Fuente: Libro "Análisis Estructural de Sectores Estratégicos"

\subsubsection{Cualitativo}

Nattermann (Nattermann, 1980) establece que para poder realizar un análisis cualitativo del hacinamiento sectorial completo se debe realizar una valoración de las características de producto, en pro de definir el posicionamiento dentro del sector de las compañías frente a sus competidores.

Para hacerlo se deben tener presentes los atributos físicos del producto o servicio y el entorno económico en el que se desarrollan las compañías (canales de distribución, promoción y localización de actividades). 


\subsection{Turbulencia}

Dentro de los conceptos de mayor interés que se presentan en la estrategia empresarial se encuentra la permanencia de las organizaciones en el tiempo, factor de relevancia para la dirección de las organizaciones quienes sufren en los mercados en la actualidad de turbulencias sectoriales y que exigen de los empresarios desarrollar para sus organizaciones herramientas que les permita ser competitivas y reaccionen con más eficiencia a los entornos que cada vez son más complejos y cambiantes. En la actualidad las tasas de empresas nacientes y de empresas que salen de los mercados se han disparado respondiendo a factores como la tecnología y la información. La turbulencia se presenta por el alto índice de entrada de nuevos competidores que no tienen una relación directa con su permanencia en el mercado. Alfred Marshall (1920), intenta explicar mediante la metáfora del "Bosque" como los arboles jóvenes crecen al transcurrir el tiempo dando como resultado el desplazamiento de los arboles más longevos. Mas sin embargo, Marshall concluye que este proceso de transición es lento. Para la época actual, las empresas emergentes han dinamizado una industria, producto de factores como las tecnologías de la información y la comunicación y el internet, el acceso más fácil al mercado bancario, lo que genera mayor intensidad a esa turbulencia industrial, competencia entre empresas consolidadas con un sin número de empresas nuevas, muchas de ellas con mortalidades elevadas que imprimen mayor velocidad a la turbulencia industrial. (Cantor, 2016) 
Los primeros autores que relacionan la turbulencia sectorial con la administración o management fueron Emery y Trist en su libro The causal texture of organizational environments quienes describen la turbulencia sectorial como un entorno cambiante y dinámico, caracterizado por la incertidumbre de variables desconocidas. Para Emery y Trist (1965) en la revista Investigación y Reflexión de la Universidad Militar Nueva Granada, Rivera-Rodriguez H, (2010), “turbulencia es la inestabilidad o tasa de cambio subyacente en el ambiente de las organizaciones; es una situación donde los recursos y restricciones cambian constantemente, obligando a las empresas a reaccionar”.

Décadas después, la turbulencia sectorial fue analizada por David (Audretsch, 1995, págs. 441-457), interpretando el dinamismo entre la entrada y la salida de competidores que se da en el mercado y que afecta a las empresas más débiles y de reacción tardía a los cambios que se presentan. Interpreta la turbulencia como dos fuerzas generadas en la relación de entrada y salida de empresas en el mercado. La primera fuerza es la que ejerce la empresa nueva que ingresa al mercado y que lleva a las demás a su desplazamiento y una segunda fuerza que es generada por la salida de empresas que pierden en la competencia por su falta de reacción y que dejan un vacío en el mercado para las potenciales empresas que ingresan a este nuevo mercado.

Para la década de los setenta, los conceptos de turbulencia se mantenían inmutables, autores como Galbraith y Khandwalla planteaban que la turbulencia sectorial se presentaba por los cambios que tenían que afrontar las organizaciones donde sus principales características se centraban en la falta de previsión y los cambios que se 
presentaban en los contextos tecnológicos, científicos y económicos, que se caracterizaban por ser cambios más rápidos que en décadas anteriores.

Emery y Trist plantean cuatro diferentes fenómenos de turbulencia sectorial: establealeatorio, placido-agrupado, desordenado-reactivo y turbulento. De este último se desprenden dos conceptos que pretenden completar la estructura de la turbulencia sectorial. Se determina que en la turbulencia sectorial se presentan contextos de dinamismo e incertidumbre y ellos son dos variables por determinar para entender los cambios a los cuales se ven sometidas las organizaciones.

Luego de los aportes de diferentes autores durante las décadas de los setenta y ochenta, el concepto de turbulencia sectorial se perfecciono entendiéndose que "se genera por varios eventos que confluyen, de manera simultánea e impredecible, y afectan el desarrollo normal de las actividades del sector. Este fenómeno tiene tres elementos que son el dinamismo, la incertidumbre y la complejidad" (Archila Saa, Figueroa Garcia, Leal Vergara, Ortega Torres, \& Rivera Rodriguez, 2011).

A partir de allí, se considera que estos tres elementos son constitutivos de la turbulencia sectorial, donde la incertidumbre según la Real Academia de la Legua, la falta de certidumbre, siendo la certidumbre la certeza, aportes de Duncan (1972) permiten entender que la incertidumbre es la asignación de probabilidades a los eventos y resalta que es la incapacidad que tienen las organizaciones de asignar de forma confiable, probabilidades que le permitan entender como los factores internos y externos a la organización inciden en los resultados de las organizaciones. Duncan concluye que la incertidumbre se entiende como una percepción de los miembros de la organización de 
carácter individual por cada uno de los integrantes de las altas gerencial influida por la tolerancia a las mismas, factores grupales como un entorno de grupo con características convergentes o divergentes, factores organizacionales como su propia estructura y factores estratégicos Oreja y Yanes (2003).

Para Oreja y Yanes (2003, p. 249) citando a Thomson (1967), "la incertidumbre se elige como el principal problema de las organizaciones complejas, y junto a su tratamiento, constituye la esencia del proceso administrativo."

El segundo concepto de la turbulencia sectorial es el dinamismo, este a diferencian de la incertidumbre, si tiene clara las variables que afectan el entorno de la organización, de lo que se encarga es de entender las variaciones o cambios de dichas variables y con ella se entiende que la toma de decisiones no solamente se puede basar en datos históricos, sino que permite entender que el dinamismo responde a hechos de la actualidad que afectan el contexto en el cual opera las organizaciones y de cómo las acciones tomadas a partir de la actualidad afectan el futuro.

Para Franco (2012) citando a Rabetino (2007, p.17) afirma que "no existe un marco teórico único, completo y generalmente aceptado para explicar las causas y los determinantes de la expansión de las empresas”. Franco (2012) citando a Penrose (1959) quien sugiere que "los recursos estratégicos de una empresa son importantes para su dinamismo. Ella definió una empresa como una colección de recursos productivos y describió como los actuales recursos junto con las oportunidades para su expansión, limitan la dirección y la velocidad del futuro crecimiento de la misma. 
En la actualidad, el dinamismo empresarial es estimulado por los entes gubernamentales y estatales que con políticas pretenden impulsar la creación de nuevas empresas que reactiven sus economías nacionales y políticas de favorezcan la supervivencia y fortalecimiento de las que ya se encuentran en operación. Políticas comerciales y empresariales como la Ley 1258 de 2008, decreto 2020 de junio de 2009, ambas con base en la ley de emprendimiento 1014 de 2006, permitieron el nacimiento de una Sociedad Simplificada por Acciones SAS, como puesta en marcha de la iniciativa del gobierno colombiano para facilitar la creación bajo un marco legal de nuevas sociedades con ventajas frente a las sociedades convencionales. Para Bellido (2010, p. 8) "Esta decisión simplemente nos muestra que las sociedades por acciones simplificadas contemplan mayores ventajas en su constitución y funcionamiento que las que se ofrecían con las sociedades unipersonales".

Muchas de estas medidas fomentan la creación de nuevas pymes con resultados que impactan directamente el dinamismo sectorial. Es así, como las empresas constituidas y con tradición en los mercados, se enfrentan a oleadas de nuevos competidores, que afrontan las barreras de entrada y supervivencia de manera más fácil.

Para Morales y Peña (2003, p. 162) “las ventajas de carácter intangible pueden ser aún mejor aprovechadas, sobre todo si estas van encaminadas hacia la consecución de un efectivo aprendizaje organizacional. Sin duda alguna, una amplia y eficiente aplicación de estas políticas pueden afectar de manera notable el dinamismo de las nuevas empresas en nuestro entorno" 
Y por último se aborda el concepto de complejidad que se entiende como la homogeneidad o heterogeneidad de los factores externos que tiene que enfrentar la organización entendiendo los factores como los políticos, ambientales, económicos, tecnológicos, diversidad de productos y servicios, sociales, aumento den la competencia entre otros.

El sector de los centros comerciales en Colombia, que durante las décadas de los 90 e inicios de los 2000 se caracterizaba por administrar los espacios dentro de su infraestructura como propiedades horizontales, durante la última década entró en un dinamismo por el arribo al país de operadores internacionales como Mall Plaza y Parque Arauco de Chile, Sprectum de Guatemala, Grupo Roble de El Salvador y Sonae Sierra de Portugal, especializados en el alquiler de locales, trayendo consigo el concepto de Tenant Mix.

Para finales de los noventa y principios de los años 2000, se desarrolló el concepto de Tenant Mix, según Caprón (1997) citando a Sassen S (1991), En la última década, el proceso de globalización de la economía ha tenido fuerte impacto sobre la reorganización territorial interna de metrópolis que van configurando un "sistema urbano transnacional". Para Capron, el Tenant Mix se encuentra compuesto desde Huaman, B., \& Lucila, M. (2016), como todo lo relacionado con el equilibrio ideal entre productos y servicios que el centro comercial toma en cuenta para el segmento meta hacia el que se dirige. El concepto de Tenant Mix, permitió el arribo al país de marcas internacionales de prestigio como H\&M, Crate \& Barrel, Bath and Body y fortaleció las que ya habían incursionado en el mercado colombiano como Zara, Massimo Dutti, American Eagle, 
Boss entre otros según la revista NewsPaper (2018), generando una competencia entre los centros comerciales de tradición en Bogotá como Unicentro y Gran Estación y los nuevos centros comerciales con el nuevo modelo de comercialización de espacios como Parque La Colina, Fontanar, Multiplaza y Plaza Central.

Para el año 2008, según el boletín de la OTC (observatorio tecnico catastral), en bogotá registraban 308 centros comerciales que sumaban en total más de 32 mil con un área de más de 100 hectáreas. Se registraban un promedio de 104 locales en promedio por centro comercial de aproximadamente $30 \mathrm{~m} 2$.

Ya para el año 2012, según el boletín de la OTC, en Bogotá los centros comerciales ascendieron a 330 con un incremento en área de más de $46 \%$ alcanzando las 146 m2. Asi mismo el promedio de locales por centro comercial se mantuvo estable más sin embargo el área promedio de cada uno de ellos aumentó en más de 12 mts2.

Para Diana Patricia Arbelaez, Presidenta y Ceo de la revista Equipar (2017), “Los centros comerciales en colombia siguen gozando de buena salud, lo cual se refleja no solo en la cantidad de nuevos proyectos con lo que cerrará este 2017, sino también en las ampliaciones, remodelaciones y modernizaciones de centros comerciales ya existentes. Según Acecolombia, gremio que asocia a los centros comerciales en Colombia, para el año 2017 se proyecta la apertura de al menos 22 nuevos centros comerciales sumando 565 mil metros cuadrados en 16 ciudades. De estos 5 son el Bogotá y 1 en Soacha que suman más de 130 metros cuadrados distribuidos en Castilla C.C. con 35 mil metros cuadrados, Multiplaza La Felicidad con 65 mil metros cuadrados BD Bacatá con 6 mil 
metros cuadrados, Usaquén Plaza con 5 mil metros cuadrados y Gran Plaza Bosa con 22 mil metros cuadrados.

\section{Gráfico 3. Crecimiento Acumulado de las Ventas de los Centros Comerciales}

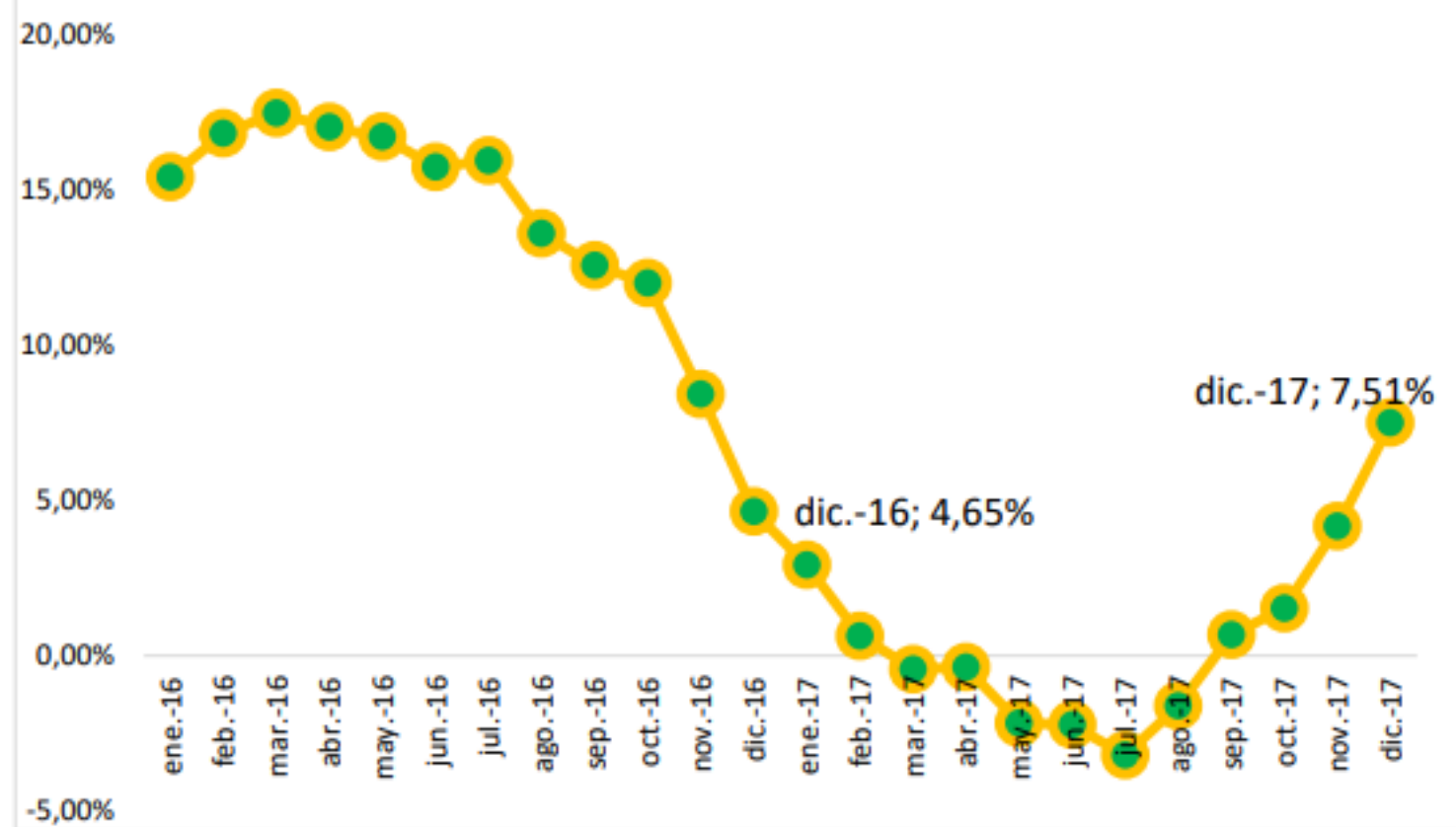

Fuente: obtenido de Raddar.net

Para el presente año según larepublica.co con fuente de Colliers International, en Bogotá el inventario en mts 2 es de 1.5 millones con un aumento de $16 \%$ frente a 2016 , con una oferta de más de 90 mil metros cuadrados con proyección de expansión a cuatro años de 16 proyectos más. Según el artículo, el precio de venta por metro cuadrado está en 20 millones de pesos y en renta de 123 mil pesos.

Como se ve en la gráfica 4 , se puede ver que las preferencias de los consumidores han cambiado, y lo que se creía antes que era un espacio público para compra de vestuario y calzado no es la principal razón para visitar los centros comerciales, como se refleja en la 
gráfica en los último 3 años ha disminuido un 9\%, mientras que las otras opciones como lo es la educación, la comida fuera del hogar y el transporte y a comunicación aumentaron un 20, 18 y 14 puntos porcentuales respectivos, lo que llega a entender que ahora los centros comerciales deben cambiar las formas en que hacen las cosas, para poder mantenerse en este mercado tan competitivo.

Gráfica 4. Ventas de los centros comerciales

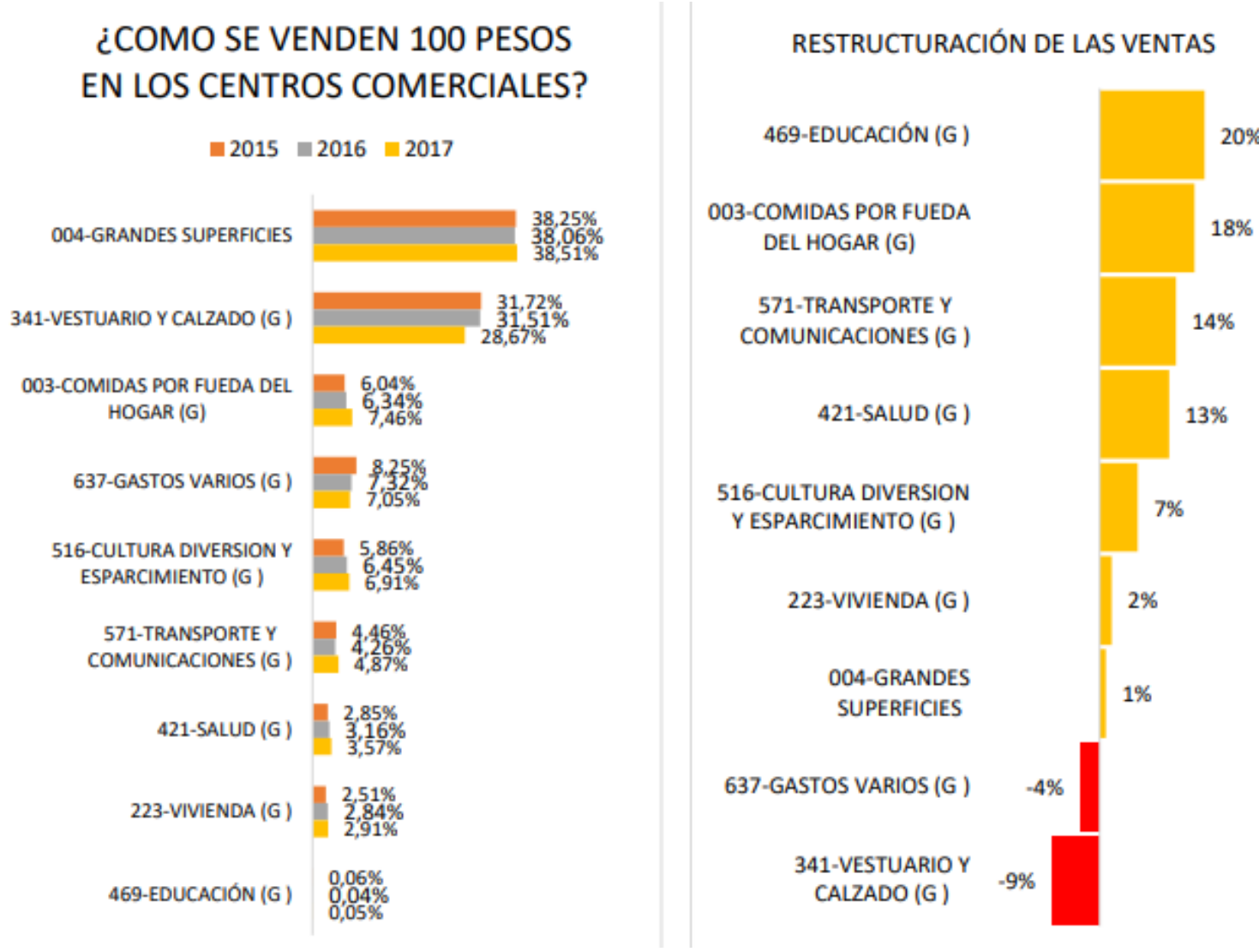

Fuente: obtenido de Raddar.net

Bajo las anteriores perspectivas, para el año 2018 se estima que se abrirán en Bogotá 5 centros comerciales como lo son El Edén Centro Comercial, Gran Plaza Ensueño, Usaquén Plaza el cual no pudo ser inaugurado en el 2017, Plaza Claro y Neos Moda. 


\subsection{Marketing Mix}

Para desarrollar un mejor análisis frente al hacinamiento sectorial se debe realizar una observación del marketing mix del mercado en el que se desenvuelven las empresas. Este se compone de los siguientes elementos:

a) Precio:

- Listado de precios del mercado.

- Descuentos ofrecidos a los consumidores.

- Periodos de pago.

- Medios de pago

b) Producto

- Tecnología

- Tiempos de entrega

- $\mathrm{I}+\mathrm{D}$

- Servicio post venta

c) Plaza

- Cobertura

- Infraestructura

- Cadena 


\section{d) Promoción}

- Publicidad

- Promociones

- Relaciones Publicas

\subsection{Panorama Competitivo}

Según Porter en 1987 (Rodriguez H. A., 2004), la empresa es contemplada como un conjunto de actividades que añaden valor al producto o servicio generado por la organización, cuya meta principal es diseñar, fabricar, comercializar y entregar el producto al consumidor final. De la misma forma es una herramienta estratégica que contribuye a la obtención de una ventaja competitiva donde el valor es aquella cantidad dispuesta a pagar por el comprador, por los atributos que ofrece una empresa en sus productos.

En la cadena de valor encontramos dos tipos de actividades: Actividades primarias y actividades de apoyo. "Las primarias son aquellas que contribuyen a la creación física del producto o servicio, su venta y transferencia al cliente y sus servicios postventa" (Porter M., 2002, pág. 68), las actividades de apoyo añaden valor a través de importantes relaciones a la empresa en colaboración con las actividades primarias. La ventaja competitiva establece el papel primordial en el desarrollo y crecimiento organizacional de las empresas. Con base en el planteamiento anterior, las organizaciones se deben enfocar en el desarrollo de actividades empresariales para lograr un valor agregado que les permitan desarrollar productos y/o servicios perdurables en el tiempo, que no se vean afectados por las enfermedades que el sector pueda llegar a adquirir. 


\section{Gráfica 5. Cadena de Valor y Cadena de Suministros}

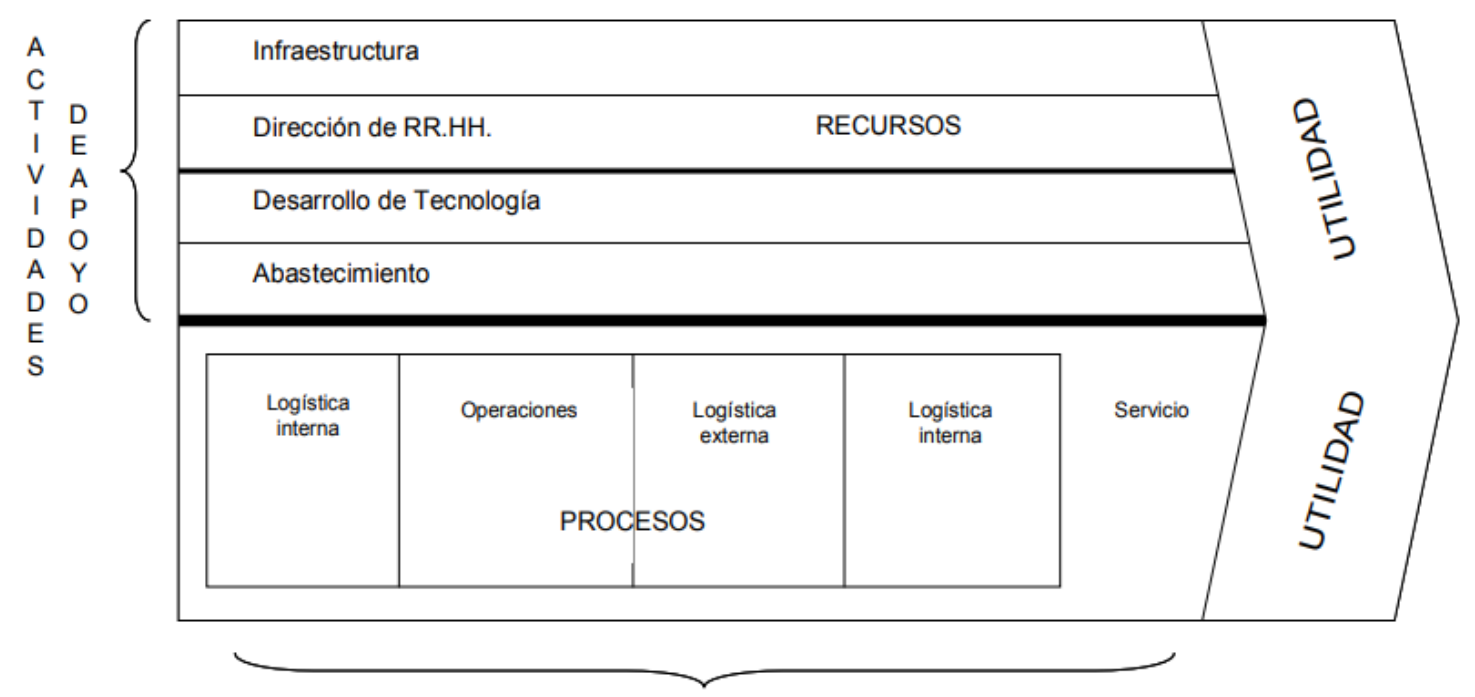

ACTIVIDADES PRIMARIAS

Fuente: obtenido de https://www.atic.cl/cadena-del-valor-analisis-perfiles-la-estrategia/

El panorama competitivo es la técnica empleada para determinar las manchas blancas que existen en el sector de estudio. Una mancha blanca es el nombre que reciben las oportunidades que no se cubren en la relación producto-mercado de las actuales unidades de negocios, en otras palabras, los espacios de mercado que se encuentran débilmente atendidos o son inatendidos totalmente. Esto permite contar con una visión permanente de todas las posibilidades presentadas a un grupo de estrategia, cuyo fin es la explotación y maximización de las nuevas variedades, las nuevas necesidades o los nuevos canales de distribución. Según Porter (Puerta, 2004) el levantamiento del panorama permite lograr una mejor posición estratégica dentro del sector que surge de tres fuentes diferentes las cuales son posicionamiento basado en variedad, necesidad y canales de acceso. 
La amplitud o estrechez del panorama está relacionada directamente con los competidores: es decir, un panorama amplio implica tener en cuenta un amplio rango de segmentos de productos y compradores, pero en otros se hace necesario requerir de alianzas, integraciones y de productos complementarios para poder ser competitivos. Como existen muchas formas de segmentar, las estrategias, a su vez pueden contener un poco de panorama amplio, como de uno más estrecho (Rodríguez \& Puerta, 2008)

\subsection{Estructura del Panorama Competitivo}

La realización del panorama competitivo, brinda un apoyo frente a las decisiones estratégicas de las empresas ya que se puede generar una radiografía del sector, con la cual se llega a evidenciar la totalidad de posibilidades estratégicas para dichas empresas. Para llegar a identificar el panorama sectorial se puede hacer uso de una matriz $\mathrm{T}$ o de un paralelepípedo estratégico, los cuales necesitan para su construcción de tres vectores específicos: necesidades, canales y variedades.

\section{Gráfica 6. Estructura del panorama competitivo}

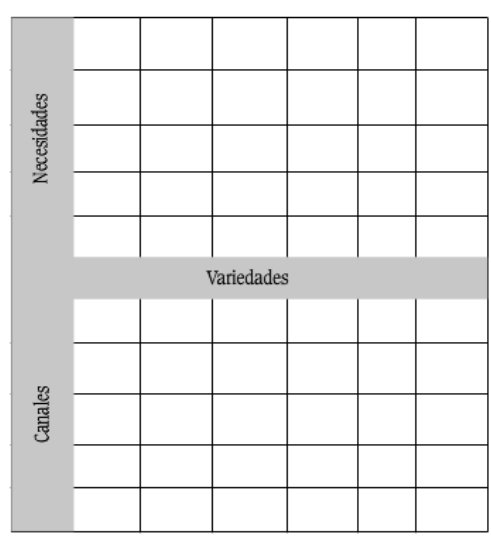

1 a. Matriz "T"

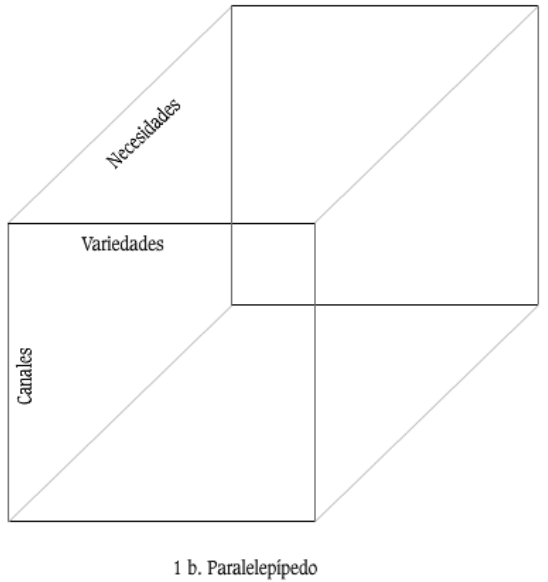

1 b. Paralelepípedo

Fuente: Libro "Análisis Estructural de Sectores Estratégicos" 
a) Necesidades: Este vector debe contener la totalidad de las necesidades que se satisfacen en el sector de estudio. Las necesidades se pueden clasificar en las necesidades del usuario (consumidor final) y necesidades del canal (intermediario). Adicional a esta clasificación, también se puede tener presente la pirámide de necesidades de Maslow, en la cual, las necesidades se dividen en cinco grupos: necesidades fisiológicas; necesidades de seguridad; necesidades sociales; necesidades de estima; y necesidades de realización. (Pichère, Cadiat, \& Serra, 2026).

b) Variedades: En este se establece la totalidad de los productos o servicios que se ofrecen en el sector estratégico que se está estudiando.

c) Canales de distribución: Este vector está compuesto por los medios a través de los cuales el cliente adquiere los productos o servicios ofrecidos en el mercado.

Se establecen estos tres vectores teniendo en cuenta que según Porter (Puerta, 2004), para que una empresa logre tener un posicionamiento en el mercado debe tener presente tres fuentes, la variedad, las necesidades y el segmento de los clientes, fuentes que están directamente relacionadas con dichos vectores. Adicionalmente tanto la publicidad como el precio son excluidos al momento de establecer los vectores principales ya que según estudios realizados en el libro "el hacinamiento, la enfermedad que los estrategas deben curar”, estos son efectos de la convergencia que se pueda presentar en un sector. 
El modelo básico también conocido como panorama bidireccional define de forma cualitativa y cuantitativa los factores que se deben considerar en la estructuración de un sector específico. De esta forma se ha llegado a un modelo en el que el interés es hacer énfasis en los aspectos competitivos de perdurabilidad de una empresa del sector en el cual se encuentra. La metodología que emplea este enfoque se basa en una organización bidimensional de variedades vs. Parámetros (necesidades y canales) asociados a organizaciones presentes en el sector (Johann Heinz Martínez Huartos, 2011).

\section{Gráfico 7. Modelo básico del panorama competitivo}

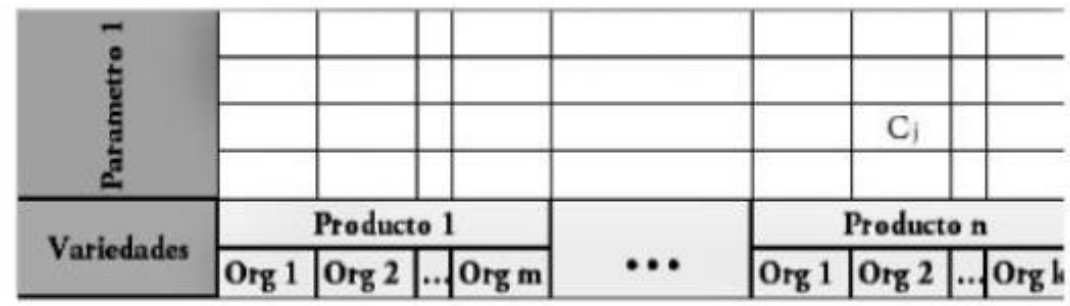

Fuente: Libro "Análisis Estructural de Sectores Estratégicos"

\subsubsection{Levantamiento del panorama competitivo}

Para facilitar el proceso de construcción del panorama competitivo, Rodríguez, H. A., \& Puerta, L. F en su libro "el hacinamiento, la enfermedad que los estrategas deben curar", establecen el siguiente algoritmo: 


\section{Gráfico 8. Proceso de levantamiento competitivo}

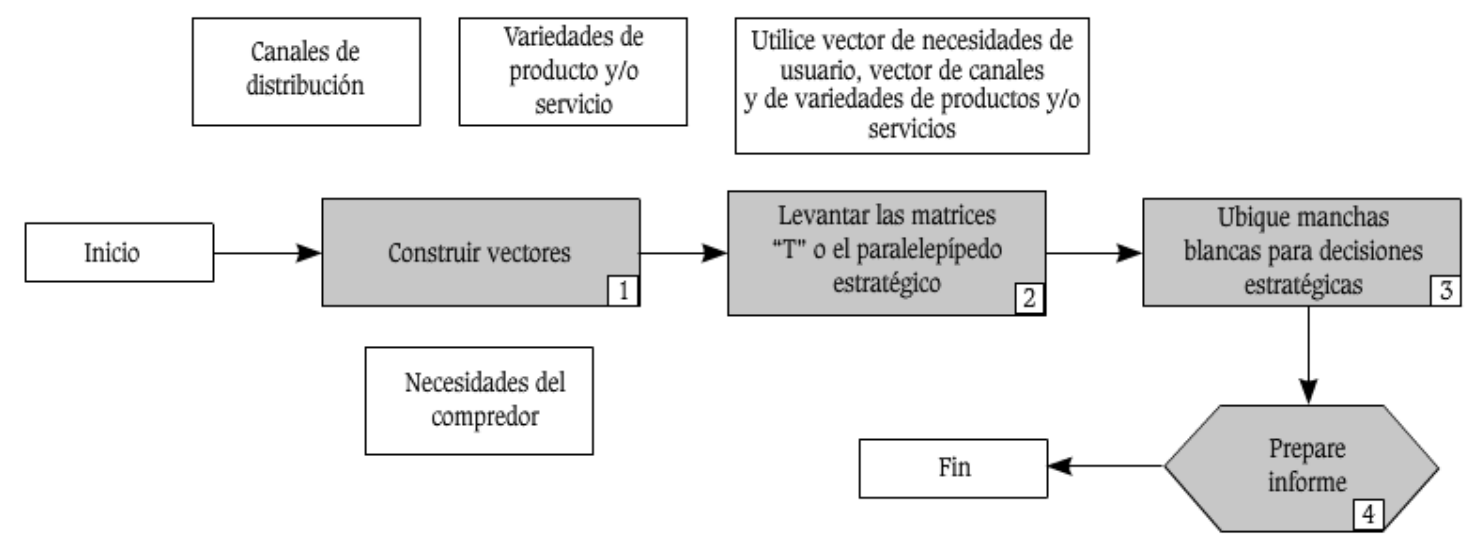

Fuente: Libro "Análisis Estructural de Sectores Estratégicos"

De este modo para la construcción de los vectores es necesario realizar encuestas a los expertos sobre los productos o servicios, características diferenciadoras, Usuarios, necesidades que se satisfacen y canales de distribución, acto seguido y contando con los vectores, se procede con la elaboración del panorama estratégico por medio de la matriz T o el paralelepípedo estratégico, en este punto es necesario identificar las empresas a analizar "rivales o competidores directos" y diligenciar las casillas identificando las necesidades, variedades y canales. Ahora se procede con la ubicación de las manchas blancas para lo cual se realiza el cruce de información, se identifica si diversas empresas satisfacen una necesidad propia del entorno de la misma forma, se determina si existen empresas con ventaja competitiva y se describen los espacios en blanco no explotados, para finalizar se genera el informe de estado del sector y las recomendaciones. 


\subsubsection{Matriz T}

Esta alternativa para el levantamiento del panorama competitivo, ayuda a comprender que canales de distribución son los utilizados por los competidores de una empresa dentro de un sector estratégico o cuales son las necesidades específicas que están siendo satisfechas dentro de este.

Como se evidencia en la siguiente gráfica en la matriz se establecen las necesidades de los clientes del sector estratégico, los canales de distribución, la variedad de productos o servicios ofrecidos y las empresas que se encuentran dentro de este sector.

\section{Tabla 1. Matriz T}

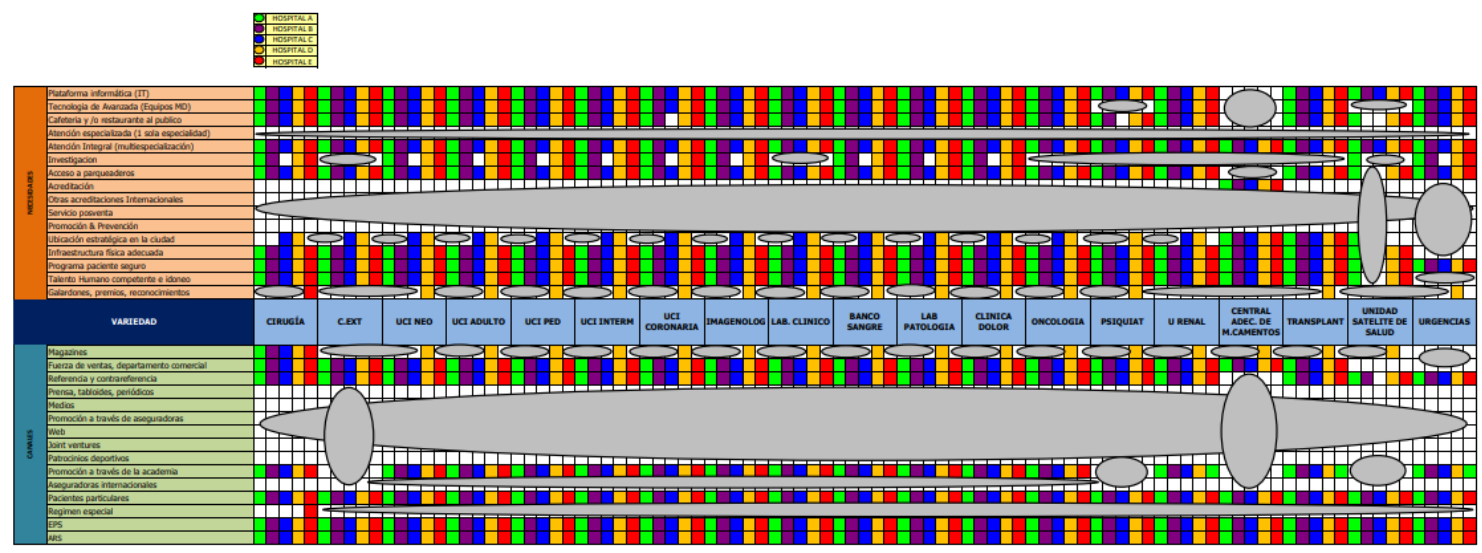

Fuente:http://repository.urosario.edu.co/bitstream/handle/10336/4304/Anexo_1_Matriz_T.pdf?se quence $=2$

a) Relación variedades- necesidades: Los espacios vacíos que se encuentren al momento de relacionar las variedades y las necesidades son mercados libres para atacar, es decir nuevas oportunidades de mercado. 
Por otro lado, aquellos espacios en los cuales se ubiquen totas las empresas satisfaciendo las mismas necesidades con la misma variedad de productos o servicios, son mercados en los cuales se puede llegar a competir por precio y a su vez, generar una erosión en la rentabilidad de las empresas que allí se ubiquen.

b) Relación variedades - canales: Si al relacionar las variedades con los canales de distribución se encuentra ubicadas todas las empresas en un solo punto, se puede concluir que este es el canal más utilizado en mercado para acercarse al cliente final, pero si se evidencia un espacio vacío esta es una oportunidad para las empresas de atacar el mercado por otro canal en el que no se tendrá un alto nivel de competencia, esto siempre y cuando genere una valor agregado a la empresa.

$\mathrm{Al}$ realizar la matriz $\mathrm{T}$, se deben responder preguntas tales como:

- ¿Qué productos están satisfaciendo las necesidades del sector?

- ¿Todas las empresas tiene el mismo target?

- ¿Qué canales están siendo utilizados en el mercado?

- ¿Qué segmentos de mercado están siendo atendidos por las empresas que están dentro de un sector estratégico?

\subsection{Paralelepípedo estratégico}

Al realizar este se puede tener un análisis más directo de lo que ocurre entre la necesidad del mercado y las variedades de productos o servicios ofertados para su satisfacción. 
Primero se deben identificar la totalidad de los vectores y sub vectores que componen el caso analizado, por ejemplo: en el sector de los lácteos se presentan tres necesidades, tres canales y tres variedades, dando un total de 27 subvectores. Así mismo, cada vector y subvector tiene un peso relativo diferente frente a los demás, por ejemplo necesidades pesa un $50 \%$, canales un $25 \%$ y variedades un $25 \%$.

Después se deben definir los paralelepípedos y sub paralelepípedos dentro del sector estratégico; la cantidad de los sub paralelepípedos sale de la multiplicación de los elementos de cada uno de los vectores identificados anteriormente. Por ejemplo, $3 \mathrm{~N}$ x $3 \mathrm{~V}$ x $3 C=27$ sub paralelepípedos. Se debe tener presente que cada uno de los sub paralelepípedos o cubos tiene un tamaño diferente ya que el peso relativo de estos es diferente.

Para finalizar se debe identificar y ubicar cada una de las empresas que se desarrollan en cada sub paralelepípedo.

\section{Gráfico 9. Paralelipedo estratégico.}

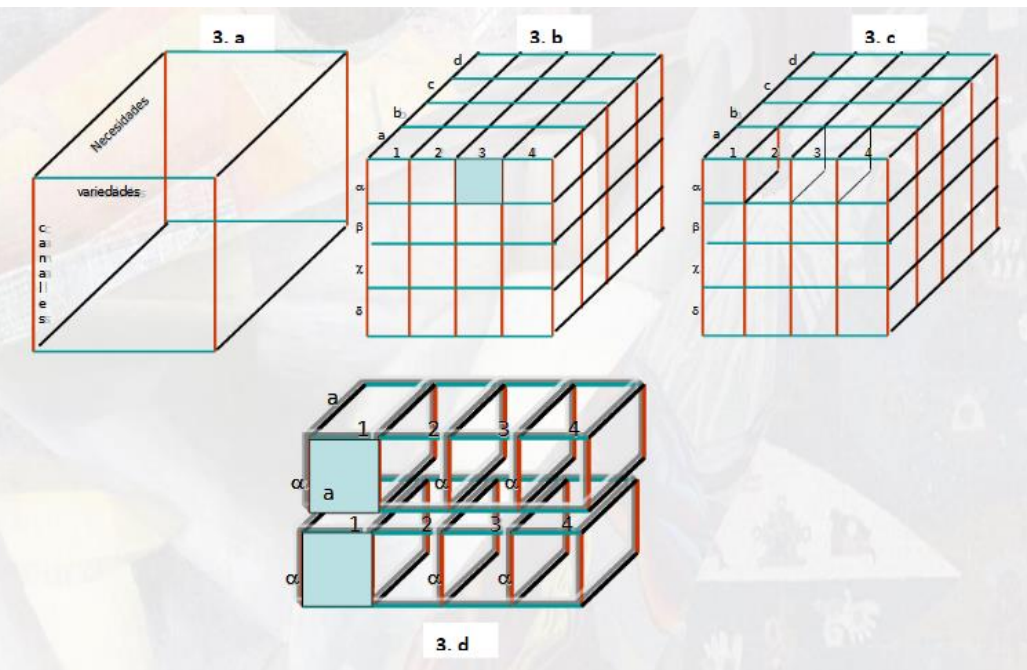

Fuente: Researchgate.net 


\subsection{Fuerzas de Porter}

La estructura competitiva de un sector está fuertemente determinada por elementos macroeconómicos, gubernamentales, tecnológicos y de otro carácter que moldean el nivel de rivalidad de una determinada industria. Por esta razón, la esencia de la formulación de una posición competitiva adecuada de una empresa en determinado sector está íntimamente ligada al análisis estructural de sus fuerzas externas. Por esta razón y en un sentido amplio, las habilidades que debe adquirir una empresa para competir adecuadamente dependerán en gran parte de la relación que ella establezca entre su posición estratégica en el mercado y las fuerzas que moldean su entorno.

Por esto, se debe comprender que el comportamiento altamente agresivo o no de sus rivales está íntimamente vinculado a la estructura económica sectorial y va más allá de comportamientos rasgos propios de cada uno de los competidores.

Para identificar de forma clara el comportamiento competitivo de un determinado sector Porter (Porter, 1998) propuso un modelo de cinco fuerzas buscando comprender los elementos estratégicos subyacentes que provocan moldean el comportamiento de un grupo de empresas rivales.

De acuerdo con Porter (Porter, 1998) la rivalidad dirige el retorno sobre la inversión de determinado sector hacia una tasa denominada piso de retorno competitivo cuando se está frente de una industria en competencia perfecta. Tasas inferiores a esta no son aceptables para ningún inversionista lo que provocará eventualmente su salida del mercado hacia otros más atractivos. Por tanto, la capacidad de un sector de entregar retornos sobre la inversión 
por encima de dicha tasa, determinará la salida de dichos capitales de sectores poco atractivos hacia otros con rentabilidad superior.

Por esto, dicho flujo de capitales es notablemente influenciado por la suma de las cinco fuerzas que reflejan el nivel de agresividad del sector. Dichas fuerzas son:

- Riesgo de entrada de los rivales.

- Amenaza de los sustitutos.

- Poder de negociación de los compradores

- Poder de negociación de los proveedores.

- Nivel de rivalidad entre competidores.

Cada uno de estos actores con competidores en sí mismos pues cada uno de ellos busca imponer las condiciones más favorables en el mercado que no necesariamente son similares a las del resto. En este sentido existe en el sector un tipo de Rivalidad extendida (Porter, 1998) que no solo tiene que ver con los rivales directos que una compañía encuentra en su sector.

\subsubsection{Riesgo de entrada}

El ingreso de nuevos rivales al sector implica que cada uno de ellos desea tomar parte del mercado que y está siendo compartido por medio de una propuesta competitiva con productos que pueden ser similares o nuevos y que en principio requieren importantes esfuerzos económicos. En general este ingreso deteriora los precios en el mediano plazo y puede provocar una importante erosión de las utilidades.

La amenaza de entrada de nuevos rivales al sector depende de la presencia de barreras de entrada y del tipo de reacción de los competidores ya existentes en el mercado. Si dichas 
barreras son altas y además la reacción de los competidores presentes es muy agresiva se puede decir que el riesgo del ingreso de nuevos rivales es bajo. Existen seis tipos principales de barreras de entrada.

- Economías de escala. Implica la reducción del costo unitario del producto (procesos o funciones incluidas en la producción de dicho producto) en un determinado periodo de tiempo. Estas economías pueden desarrollarse por medio de costos compartidos (Capacidad que tiene una compañía de distribuir en muy pocos productos del portafolio sus costos fijos debido a la utilización de varias piezas de ensamble en diferentes tipos de productos) o actividades compartidas (estrategia multinegocios en al que una UEN puede usar o vender en su mercado un producto de otra UEN).

- Productos diferenciados. Implica firmas fuertemente establecidas en el sector con marcas altamente reconocidas que provocan una alta lealtad en el consumidor.

- Altos requerimientos de capital. En sectores en los que los altos costos tecnológicos, la alta inversión en I+D son determinantes para enterar a un determinado sector con una posición competitiva firme.

- Costos de cambio. Definidos como el costo implícito que le lleva a un consumidor el cambiar el insumo de determinado proveedor que ha sido usado por largos periodos de tiempo.

- Acceso a los canales de distribución y ventas. En muchos casos los nuevos rivales deben persuadir a los canales de ventas establecidos en el sector, de aceptar sus 
productos y servicios por medio de reducción de precios lo que muchas veces deteriora sus utilidades.

- Desventaja de costos independientes a la escala: como acceso privilegiados a materias primas, patentes, Subsidios del gobierno, curvas de aprendizaje.

\subsubsection{Amenaza de los sustitutos}

Los productos sustitutos suelen poner límites al precio y por tanto a los rendimientos obtenidos en un sector en el sentido que ellos pueden llegar a reemplazar en determinado momento al producto de la industria cuando su valor percibido (relación entre precio y valor) es superior. Se debe valorar de cerca el comportamiento de ellos, en especial si son fabricados por industrias con altos rendimientos pues fortalecería su posición competitiva en el mercado.

\subsubsection{Poder de negociación de los proveedores.}

Definido como la capacidad de los proveedores del sector de incrementar los precios de sus insumos. Depende principalmente de su nivel de concentración, el grado de diferenciación del insumo ofrecido, los costos de cambio del comprador y el riesgo de integración hacia adelante que exista.

\subsubsection{Poder de negociación de los compradores}

El poder de los compradores radica en la capacidad que ellos tienen de empujar los precios hacia abajo. Esta capacidad depende de su nivel de concentración, sus economías de escala, el nivel de diferenciación del producto comprado, sus costos de cambio o el riesgo de que el comprador se integre verticalmente hacia atrás con el proveedor. 
En las cinco fuerzas de Porter el poder de negociación del comprador según Porter (1998), se refiere a la presión que pueden ejercer los consumidores sobre las empresas para conseguir que se ofrecen productos de mayor calidad, mejor servicio al cliente, y precios más bajos. Al analizar el poder de negociación de los clientes, se puede concluir que este análisis de la industria se lleva a cabo desde la perspectiva del proveedor. De acuerdo con las 5 fuerzas de Porter, el poder de compra es una de las fuerzas que dan forma a la estructura competitiva de una industria.

\subsubsection{Intensidad de la rivalidad entre competidores.}

La rivalidad ocurre cuando uno o varios competidores de un sector sienten la oportunidad o necesitan mejorar su posición competitiva. Las acciones por ellos tomadas generan presión sobre los otros de tal manera que comienza a existir un tipo de interdependencia en la que se desarrolla una dinámica de ataque y defensa competitivas. El reflejo de dicha dinámica se percibe principalmente en la mejora del valor agregado de los productos y una caída progresiva en los precios, así como en las utilidades del sector. Varios elementos moldean el grado de rivalidad sectorial.

- Crecimientos lentos de la industria que elevan el grado de rivalidad por la necesidad de crecimiento de cada uno de los rivales.

- Altos costos fijos. Si la estructura de costos de las empresas tiene un alto componente de costos fijos, estas se verá obligadas a elevar la intensidad de sus movimientos competitivos para elevar sus ingresos.

- Bajos costos de cambio de los compradores.

- Productos comoditizados. 
- Capacidad instalada ociosa en el sector.

\section{Metodología}

Esta investigación es de tipo cualitativo-descriptivo que comprende la delimitación de los hechos que conforman el problema de investigación. Se trata de describir elementos y componentes con el fin de descubrir y comprobar posibles interrelaciones entre las variables (Méndez, 2006) y de establecer comportamientos concretos. Luego del análisis de las fuentes secundarias que provean información sobre los Centros comerciales de la ciudad de Bogotá como objeto de análisis, se aplicaran encuestas y entrevistas con el fin de recopilar información más precisa para la investigación.

Las fuentes primarias de este trabajo son los centros comerciales más reconocidos por las listas económicas del país, como fuentes secundarias se encuentra un exhaustivo rastreo en páginas de internet y libros. La herramienta empleada en este trabajo son las encuestas; a través de correos virtuales y visitas empresariales; con el fin de obtener información de un campo o problema sobre lo que existen pocos datos y así determinar como ya se había mencionado las interrelaciones entre las variables. En el cuestionario que se realizará se obtendrán datos técnicos, con respecto a la infraestructura de los centros comerciales, como se encuentra distribuido, la cantidad de locales, parqueaderos, y tipos de tiendas que maneja cada uno, teniendo una muestra de 12 centros comerciales de los 20 más importantes de la ciudad de Bogotá (Dinero, 2016), representado esto el 60\%, siendo este una muestra importante como base para la investigación. 
Los centros comerciales involucrados en la investigación son: Muliplaza, Centro Mayor, Gran Estación, Hayuelos, Salitre Plaza, Portal 80, Plaza de las Américas, Titán Plaza, Unicentro y Santafé. Loa anteriores mencionados anteriormente se encuentran en diferentes sectores económicos, entre los estratos 2 a 6.

\section{Resultados o hallazgos principales.}

\subsection{Matriz $\mathbf{T}$}

Se realizó el levantamiento del panorama mediante el paralelepípedo, ya que esta permite realizar una lectura más acertada entre las variables. Day (1990) se vale de esta estrategia para identificar segmentos de mercado y hacer aplicación de estrategias para cada segmento. Las categorías se dividen en las necesidades, en variedades e infraestructura, donde cada una tiene un nivel de importancia, determinado a partir de una encuesta realizada a los visitantes de los Centros comerciales con una muestra de 107 personas.

Después de realizar la encuesta, como se ve en la gráfica 10 se determinó que el 59,8\% de la población tienen como principal punto de referencia para escoger el centro comercial por la variedad, como lo es el servicio de parqueadero, los lugares de esparcimiento, las tiendas, la variedad en comidas y espacios donde compartir con la familia, como los cinemas y centros de divertimento. El 26,2\% determino que es por la experiencia, y el $14 \%$ por la infraestructura.

\section{Gráfica 10. Matriz T}

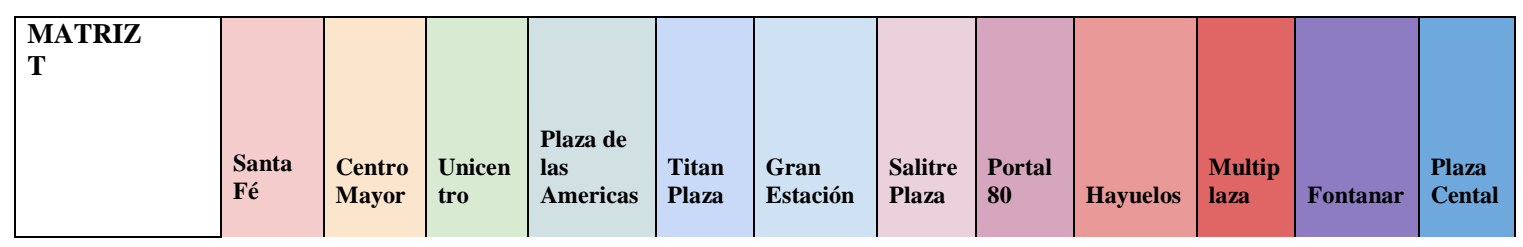




\begin{tabular}{|l|l|l|l|l|l|l|l|l|l|l|l|l|}
\hline $\begin{array}{c}\text { Categorías de } \\
\text { productos }\end{array}$ & & & & & & & & & & & \\
\hline TOTAL & 289 & 324 & 363 & 320 & 220 & 438 & 210 & 209 & 234 & 129 & 167 & 233 \\
\hline
\end{tabular}

Experiencia
\begin{tabular}{|l|l|l|l|l|l|l|l|l|l|l|l|l|}
\hline TOTAL & 305 & 341 & 378 & 338 & 234 & 454 & 224 & 226 & 251 & 149 & 184 & 247 \\
\hline
\end{tabular}

Infrastructura

\begin{tabular}{|c|c|c|c|c|c|c|c|c|c|c|c|c|}
\hline $\begin{array}{l}\text { TOTAL } \\
\text { m2 }\end{array}$ & $\begin{array}{c}244.00 \\
0,00\end{array}$ & $\begin{array}{c}248.00 \\
0,00\end{array}$ & $\begin{array}{c}126.00 \\
0,00\end{array}$ & $\begin{array}{c}237.000, \\
00\end{array}$ & $\begin{array}{l}237.5 \\
00,00\end{array}$ & $\begin{array}{c}160.000 \\
00\end{array}$ & $\begin{array}{c}85.00 \\
0,00\end{array}$ & $\begin{array}{c}81.69 \\
1,00\end{array}$ & $\begin{array}{c}140.000 \\
00\end{array}$ & $\begin{array}{l}182.0 \\
00,00\end{array}$ & $\begin{array}{c}132.000, \\
00\end{array}$ & $\begin{array}{l}205.0 \\
00,00\end{array}$ \\
\hline
\end{tabular}

Fuente: Producción propia

Gráfica 11. Encuesta de preferencia de los consumidores de los centros comerciales. ¿Que es lo que más busca en un centro comercial?

\section{7 respuestas}

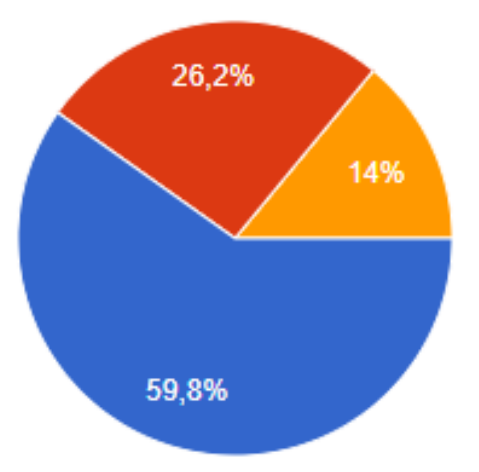

Variedad

Experiencias

Infraestructura

Fuente. Producción propia.

Una vez determinado las preferencias de los consumidores, se realiza un estudio con los centros comerciales, con respecto a la cantidad de variedad que se encuentra en cada uno, como se puede ver en la tabla 2. La categoría de variedad se organizó por tipo de servicios que ofrece cada centro comercial estudiado en la muestra anteriormente mencionada, ya diligenciado los espacios dependiendo lo que ofrecen los centros comerciales se ubican las manchas blancas, esto con el fin de identificar las decisiones estratégicas, que representa una ventaja competitiva frente a los otros, ya que es única o muy pocos ofrecen ese servicio, 
como es el caso de Salitre plaza con las Tiendas de Música, donde ningún otro centro comercial la tiene, o las tiendas naturistas que tiene Santafé que los otros no ofrecen.

Tabla 2. Paralelepípedo estratégico de los centros comerciales de Bogotá.

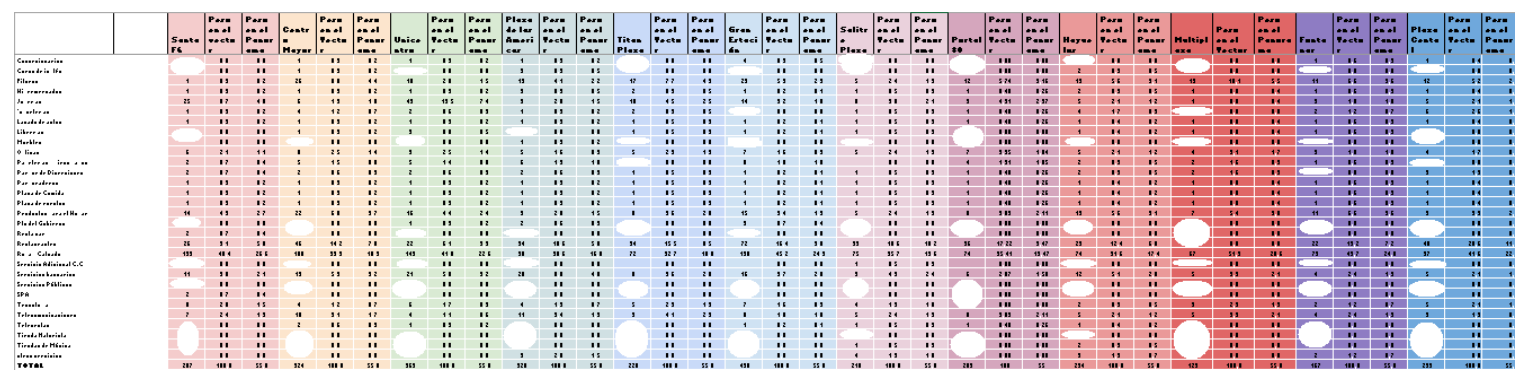

Fuente. Creación propia

Es decir, lo que es Salitre plaza y Santafé, tienen una ventaja sobre los otros, ya que se encuentran en un posición en la que la empresa es única, ya que han logrado diferenciarse por variedad.

Por otro lado, para la mayoría de los centros comerciales hay espacios no explotados como lo son los espacios de Televentas, de los 12 centros comerciales que se estudiaron, solo la mitad ofrecen ese servicio. Y solo 3 ofrecen otros servicios fuera de los convencionales, teniendo un valor agregado que los demás no ofrecen.

\subsection{Paralelepípedo competitivo}

Para conocer de manera más clara las necesidades que satisfacen los centros comerciales a los clientes, que experiencias o infraestructura ofrecen, o la relación que hay entre variedad- experiencia- infraestructura, se realiza el paralelepípedo estratégico que permite realizar hacer una lectura más directa sobre la relación de las tres categorías. Según Day (1990) se vale de esta alternativa para identificar segmentos del mercado y hacer aplicación de estrategias para cada segmento. 


\section{Gráfico 12. Paralelepípedo estratégico}

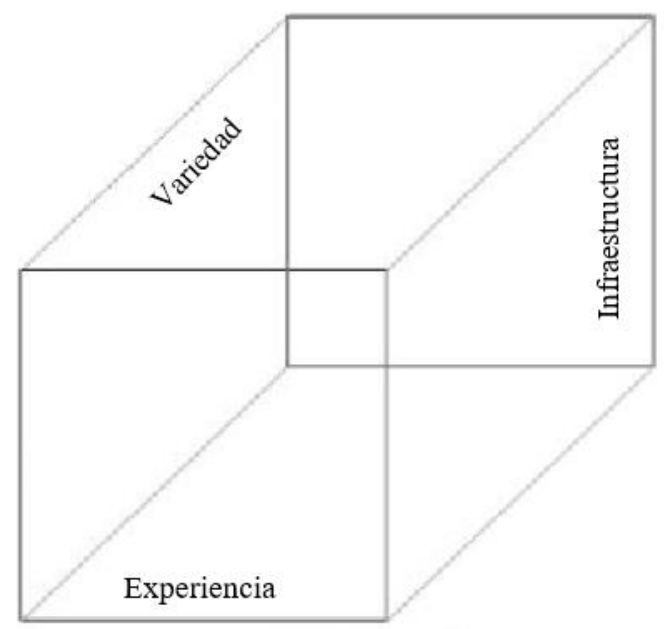

Fuente: Producción propia

Cada vector puede tener un peso relativamente distinto, para esta investigación se determinó en la importancia de cada uno por los clientes basado en la encuesta anteriormente mencionada, Quedando de la siguiente manera:

\begin{tabular}{|l|l|}
\hline \multicolumn{2}{|l|}{ Porcentajes de cada vector } \\
\hline $59,8 \%$ & Variedad \\
\hline $26,2 \%$ & Experiencia \\
\hline $14 \%$ & Infraestructura \\
\hline
\end{tabular}

En este caso, el vector de variedad fue considerado como el más importante de los tres. En cuanto a los vectores experiencias e infraestructura tienen un 26,2\% y $14 \%$ de importancia respectivamente. Al hacer una relación de componentes de mayor relevancia en el panorama éstos serían: ropa y calzado, comercio y m2 comerciales. Información que es ordinal al ser contrastada entre vectores, pero en cada uno de ellos es relevante. El paralelepípedo estratégico, cuenta con sus subparalelepídedos, donde cuenta con un total de 518, está cantidad se obtiene a partir de la multiplicación de los elementos que 
tiene cada vector. Para los centros comerciales se tiene 37 variedades, 7 de experiencia y 2 de infraestructura.

Total subcubos $=$ \# de variedades $\mathbf{x}$ \# de experiencias $\mathbf{x}$ \# de infraestructura Para la investigación se identificó como los centros comerciales se concentran en cada una de las categorías, y los más relevantes, se estudiará en detalle con los subparalelepídedos de mayor importancia, teniendo en cuenta que no todos tienen el mismo tamaño.

Como lo ilustra la gráfica 12. Los centros comerciales presentan volúmenes diferentes, pero algunos tienen características similares, esto permite de manera global determinar los más relevantes, prosiguiendo así, a entrar en estudio de los mismos.

\section{Grafica 13. Paralelepípedo de los centros comerciales}

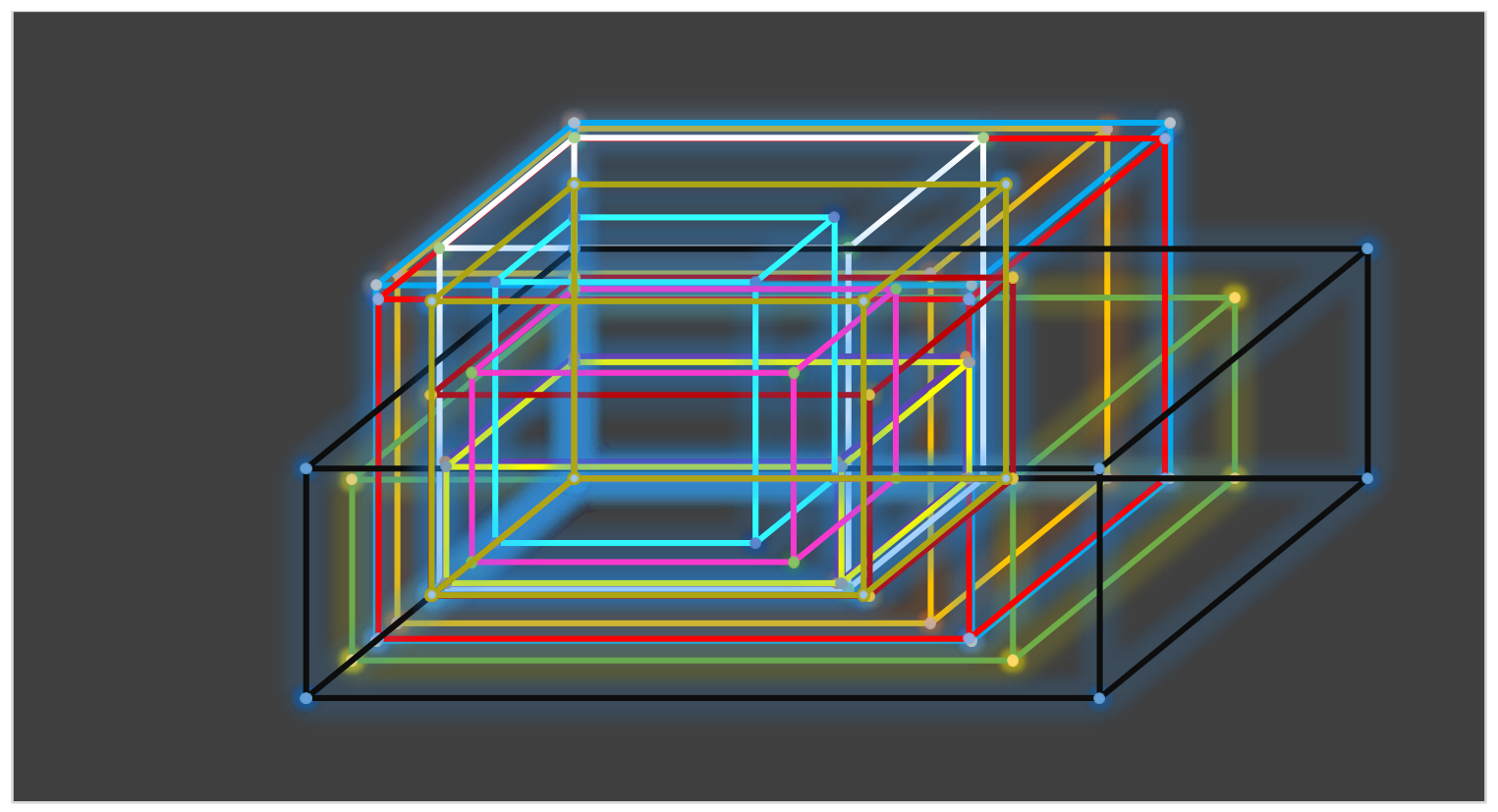

Fuente: Producción propia 


\begin{tabular}{|l|l|}
\hline Centro Comercial & Color \\
\hline Santafé & Naranja \\
\hline Centro Mayor & Azul \\
\hline Unicentro & Verde \\
\hline $\begin{array}{l}\text { Plaza De Las } \\
\text { Américas }\end{array}$ & Rojo \\
\hline Titan Plaza & Blanco \\
\hline Gran Estación & Negro \\
\hline Salitre Plaza & Lila \\
\hline Portal 80 & Amarillo \\
\hline Hayuelos & Vino tinto \\
\hline Multiplaza & Aguamarina \\
\hline Fontanar & Rosado \\
\hline Plaza Central & Mostaza \\
\hline
\end{tabular}

Por consiguiente, se realizará tres paralelepípedos por cada vector, el primero permitirá analizar los centros comerciales de mayor volumen, el segundo los dos de menor volumen, y el tercero el de mayor y menor volumen, de esta manera se podrá analizar las estrategias de los centros comerciales y poder observar el hacinamiento que se presenta en este sector.

Para los paralelepípedos de variedad y experiencia son iguales ya que los volúmenes mayores y menores de cada vector son los mismos centros comerciales, dando la oportunidad analizar el gráfico de manera más amplia.

Para el caso de los vectores de variedad-experiencia de mayor volumen se pueden identificar los C.C Gran Estación y Unicentro, siendo el de mayor tamaño Gran estación, representado por el color negro en el Grafico 13. 
Grafica 14. Paralelepípedo del vector variedad de mayor volumen

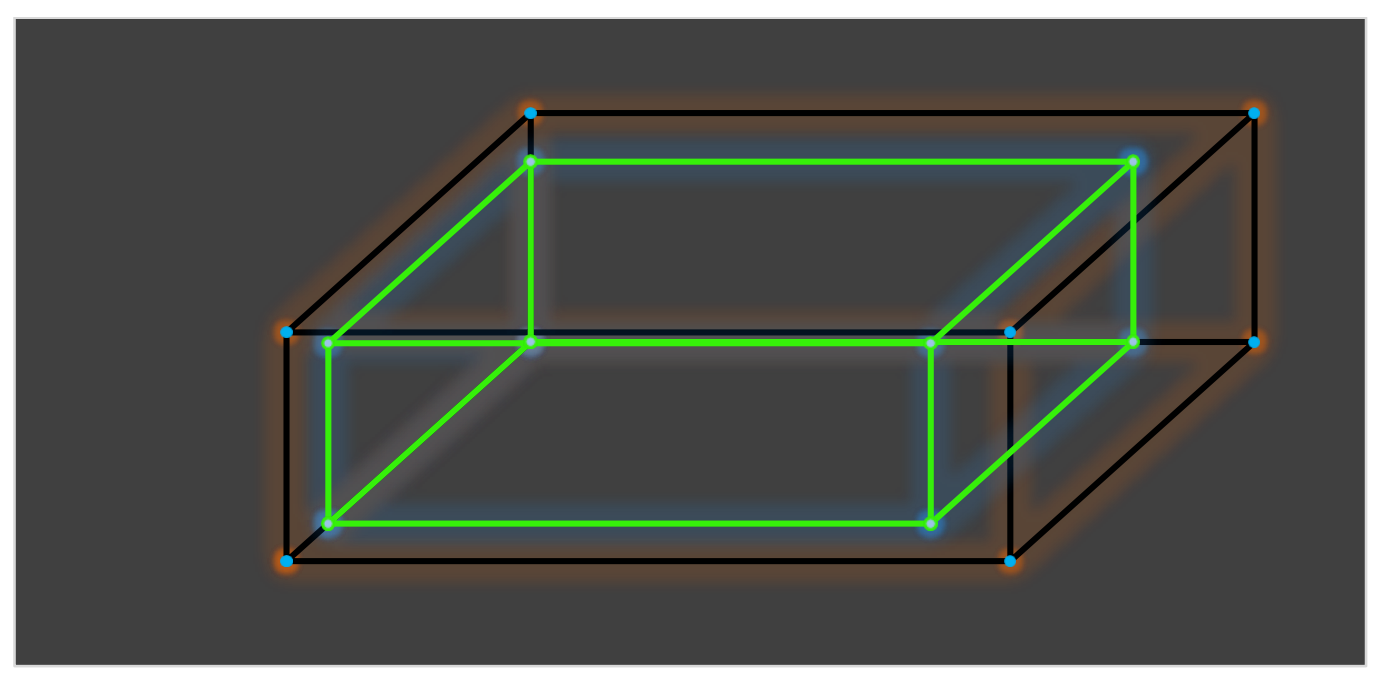

Fuente: Producción propia

A pesar de tener casi el mismo tamaño, como se puede ver gran estación supera a Unicentro en los tres vectores pero principalmente en experiencia, esto resalta la estrategia del C.C, que se enfoca en experiencia, aunque ofrezcan servicios similares y valor agregado de este centro comercial, es la experiencia, manteniendo y atrayendo mayor público.

Por otra parte, se ve reflejado el hacinamiento con este ejemplo, ya que la proporción de espacio es la misma para la variedad, en este sector lo que logra ser más competitivo un centro comercial, es la cantidad de servicios que puede lograr ofrecer, y para estos dos C.C la rivalidad se centra en eso, pero con valores agregados, como lo logra Gran Estación, permite hacer una gran diferencia en la cantidad de circulación de clientes que pueden tener en un día, afectando también a los ingresos de cada uno. 
Grafica 15. Paralelepípedo del vector variedad de menor volumen

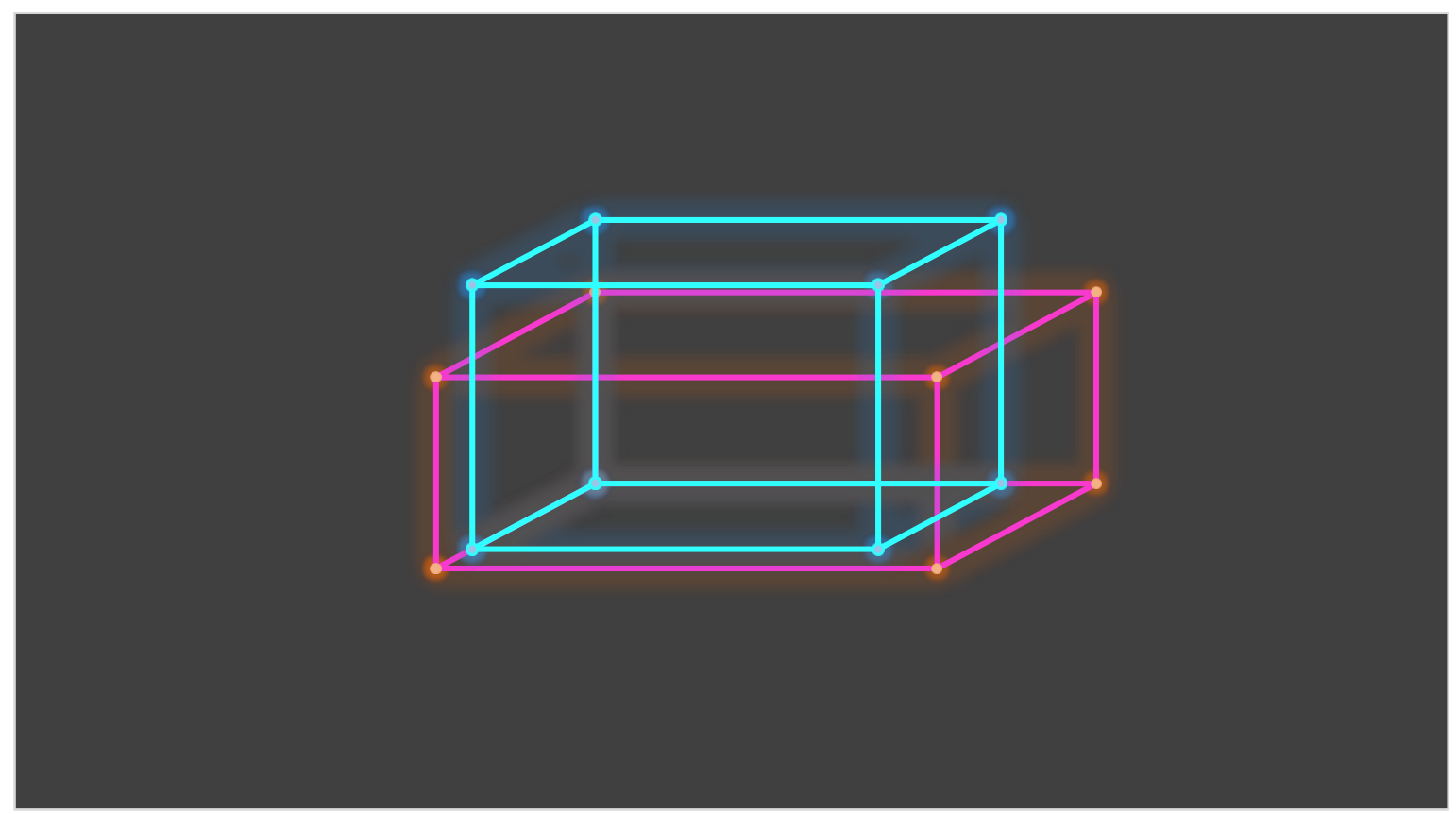

Fuente: Producción propia

Como se ve en el Grafico 14. Los dos C.C de menor volumen son Fontanar y Multiplaza, representados con el color rosado y aguamarina respectivamente. Como se puede observar en la gráfica, Multiplaza tiene mayor infraestructura pero presenta menor variedad y experiencia, reflejado principalmente en experiencia. Fontanar, por otro lado, logra suplir lo que le falta en infraestructura en experiencias. La proporción de diferencia entre infraestructura y experiencia es muy similar. Esto nos lleva a la conclusión, que el tamaño de un C.C no es el factor determinante para prestar mejores servicios, es necesario pero para a segundo plano, ya que para el cliente lo más relevante es la variedad que ofrecen esos espacios, y las experiencias que se logran tener ahí. 
Grafica 16. Paralelepípedo del vector variedad de mayor y menor volumen

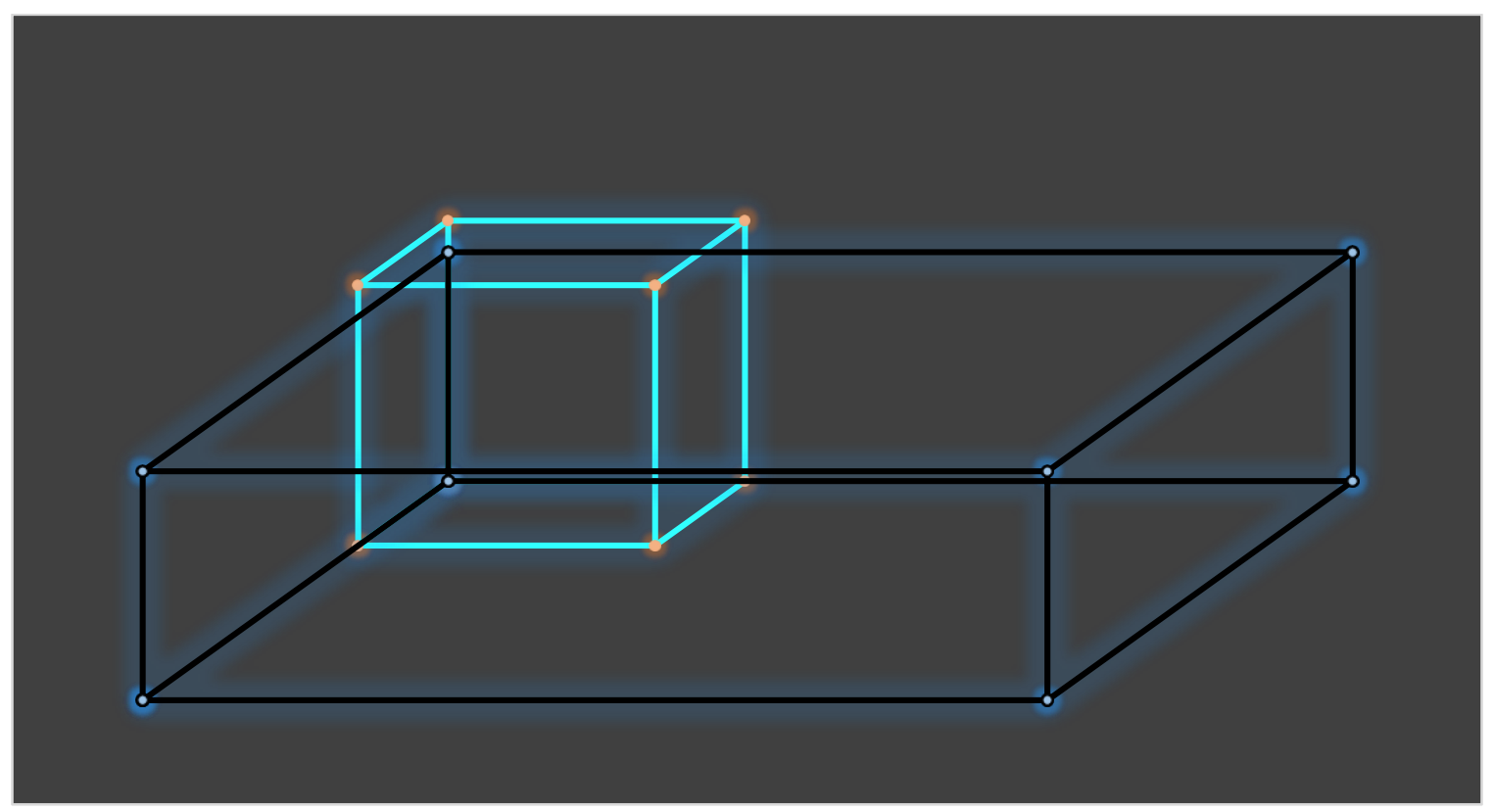

Fuente: Producción propia

En consecuencia de los dos anteriores paralelepípedos, se cogen el de mayor y menor volumen que son Gran Estación y Multiplaza. Esto nos permite ver de manera más clara y concisa, las estrategias de cada centro comercial. Al igual que el anterior grafico, se puede ver que Multiplaza tiene mayor infraestructura, pero presenta mucho menos variedad y experiencia en comparación de Gran Estación, tiene un poco menos de infraestructura, pero el aprovechamiento para ofrecer variedad y experiencia es mucho mayor.

Muliplaza se inauguró en el año 2017 un megaproyecto, ubicado en el barrio La Felicidad, en la Avenida Boyacá con Calle 13, con una vitrina comercial para más de 200 marcas nacionales e internacionales, que reúnen una gran variedad, pero lo que más los diferencia es la curva de aprendizaje, ya que Gran Estación lleva en el mercado 13 años, considerándose el quinto centro comercial más grande de Bogotá sumando sus dos 
costados unidos mediante un sofisticado puente elevado. Estando ubicado en una posición geográfica estratégica, ubicado a 15 minutos del Aeropuerto Internacional El Dorado. Con entrada de dos vías principales de Bogotá.

Cada centro comercial tiene una perspectiva diferente sobre el negocio, para Multiplaza el factor determinante, son los espacios de esparcimiento, donde el consumidor se sienta cómodo, pero no se ve reflejado de manera considerable las experiencias que puede lograr, pero tiene los recursos para hacerlo, aquí refleja una mancha blanca, que puede utilizarse a favor, generando una estrategia de mejora, aprovechando de manera efectiva sus recursos, ofreciendo mayor variedad y experiencias, poniendo la debilidad como fortaleza permitiendo ser más competitivo frente a los demás.

Grafica 17. Paralelepípedo del vector infraestructura de mayor volumen

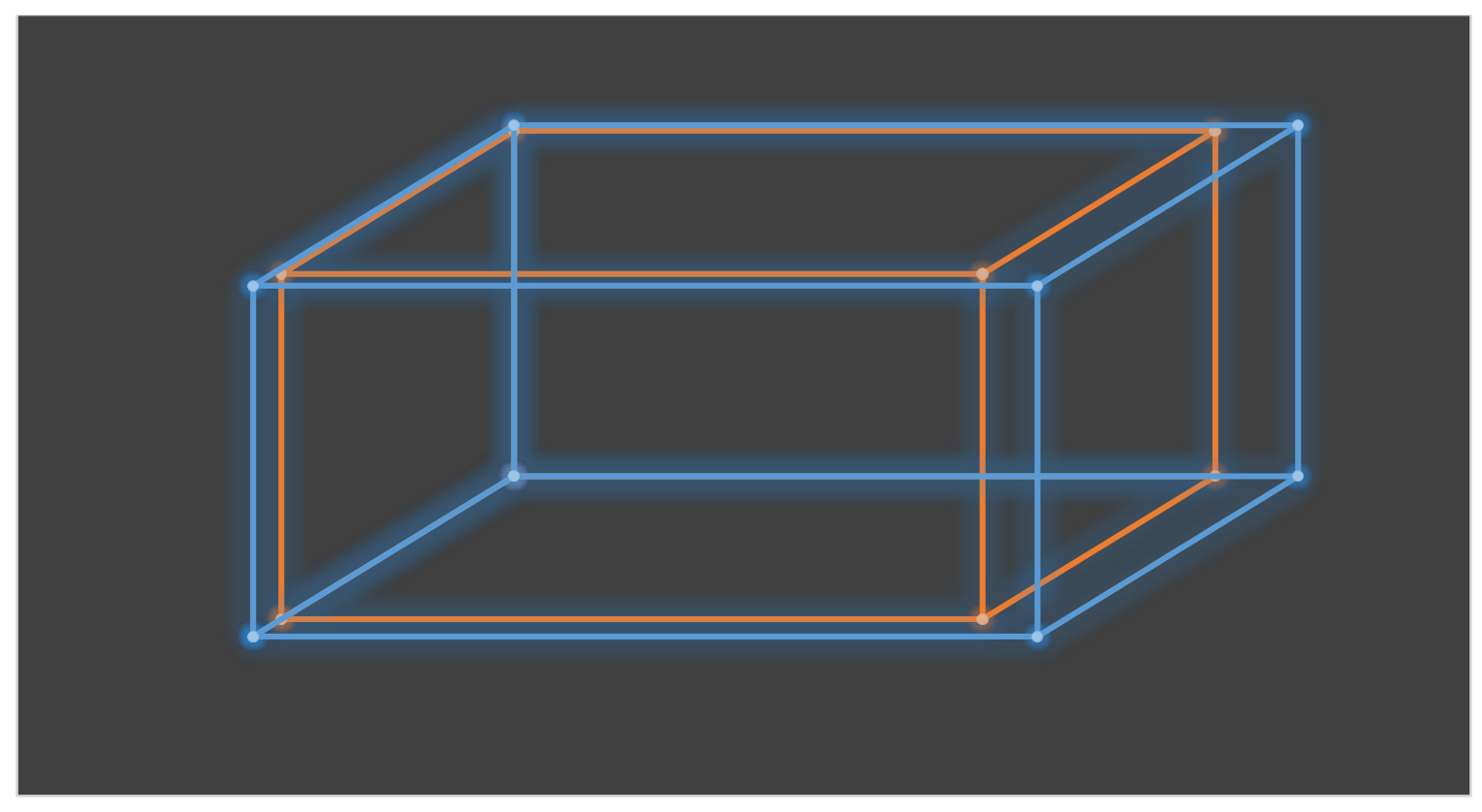

Fuente: Producción propia

En el vector de infraestructura de mayores volúmenes se encuentran Santa fé y Centro Mayor, representados con el color naranja y azul respectivamente, que se diferencian por 
$4.000 \mathrm{~m} 2$, siendo esta una diferencia mínima, pero que puede verse afectado en la experiencia y variedad. En el caso de Centro Mayor, que tiene mayor infraestructura, sabe aprovechar los espacios y con ello permite ofrecer mayor servicios y aumenta de la misma manera la experiencia que puede ofrecerle a los clientes. Por otro lado. Santa fé a pesar de que tiene casi la misma infraestructura no logra superarlo, y como ya se demostró antes, lo que logra ofrecer el centro comercial no depende de eso, dejando al centro comercial con una brecha enorme, y de la misma manera tiene una oportunidad de mejora igual de grande, ya que puede emplear estrategias enfocadas en mejoramiento de experiencias de la mano de la variedad que logre ofrecer.

\section{Grafica 18. Paralelepípedo del vector infraestructura de menor volumen}

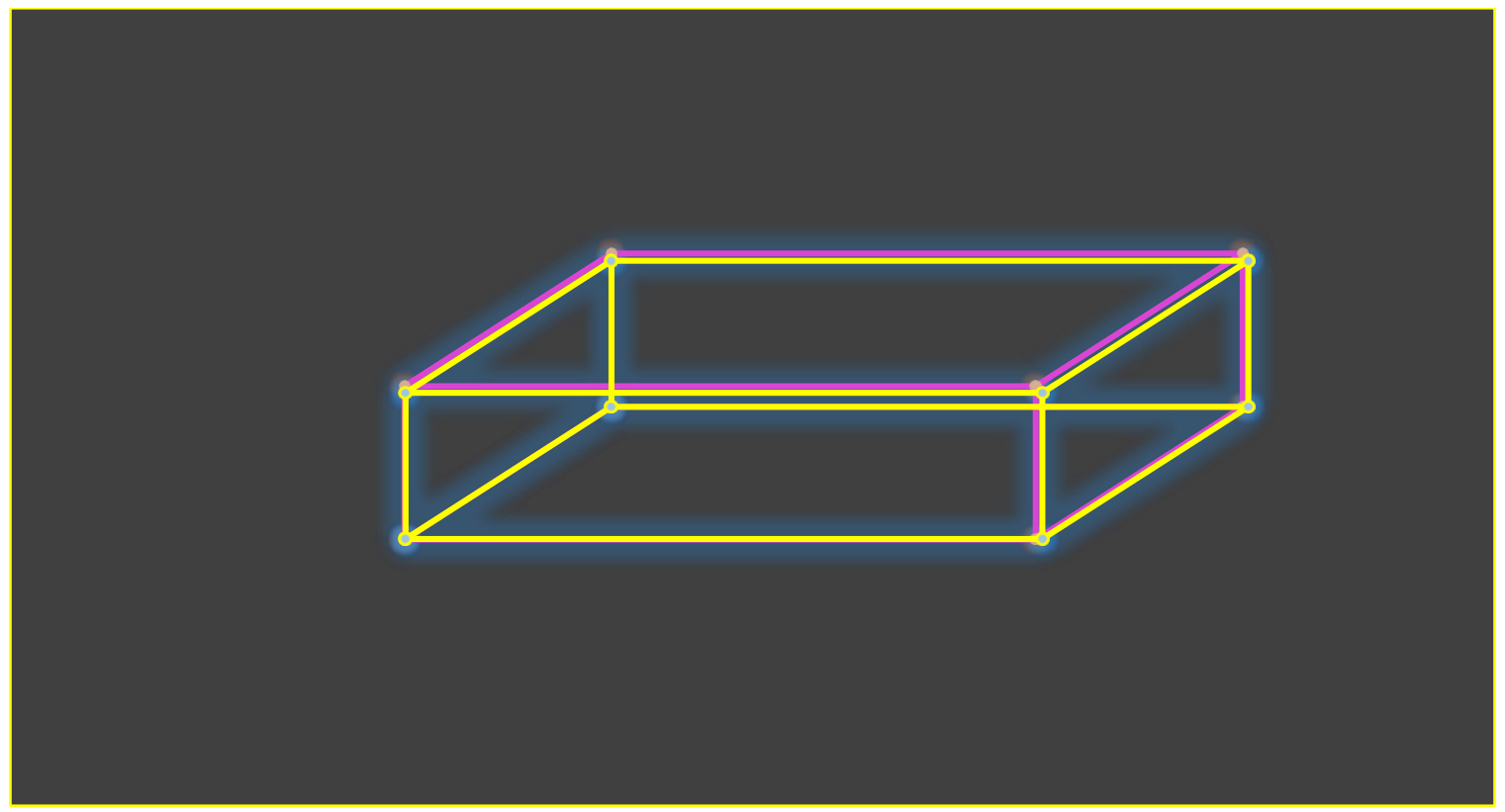

Fuente: Producción propia

Al igual que los de mayor volumen, los de menor volumen se llevan una diferencia de $4.000 \mathrm{~m} 2$, siendo el Portal 80 y Salitre plaza, representados por el color amarillo y lila respectivamente, pero el Isomorfismo puede verse muy claro, generando convergencia 
estratégica ya que presentan de manera similar la cantidad de variedad y experiencias que ofrece, ya depende del valor agregado puedan ofrecer como nueva estrategia de negocio, aprovechando la curva de aprendizaje de cada uno y del mercado, pudiendo así, salir de la monotonía y del hacinamiento que presentan los dos, saliendo de lo convencional, siendo innovadores, permitiendo aumentar la circulación de clientes en el centro comercial.

Grafica 19. Paralelepípedo del vector infraestructura de mayor y menor volumen

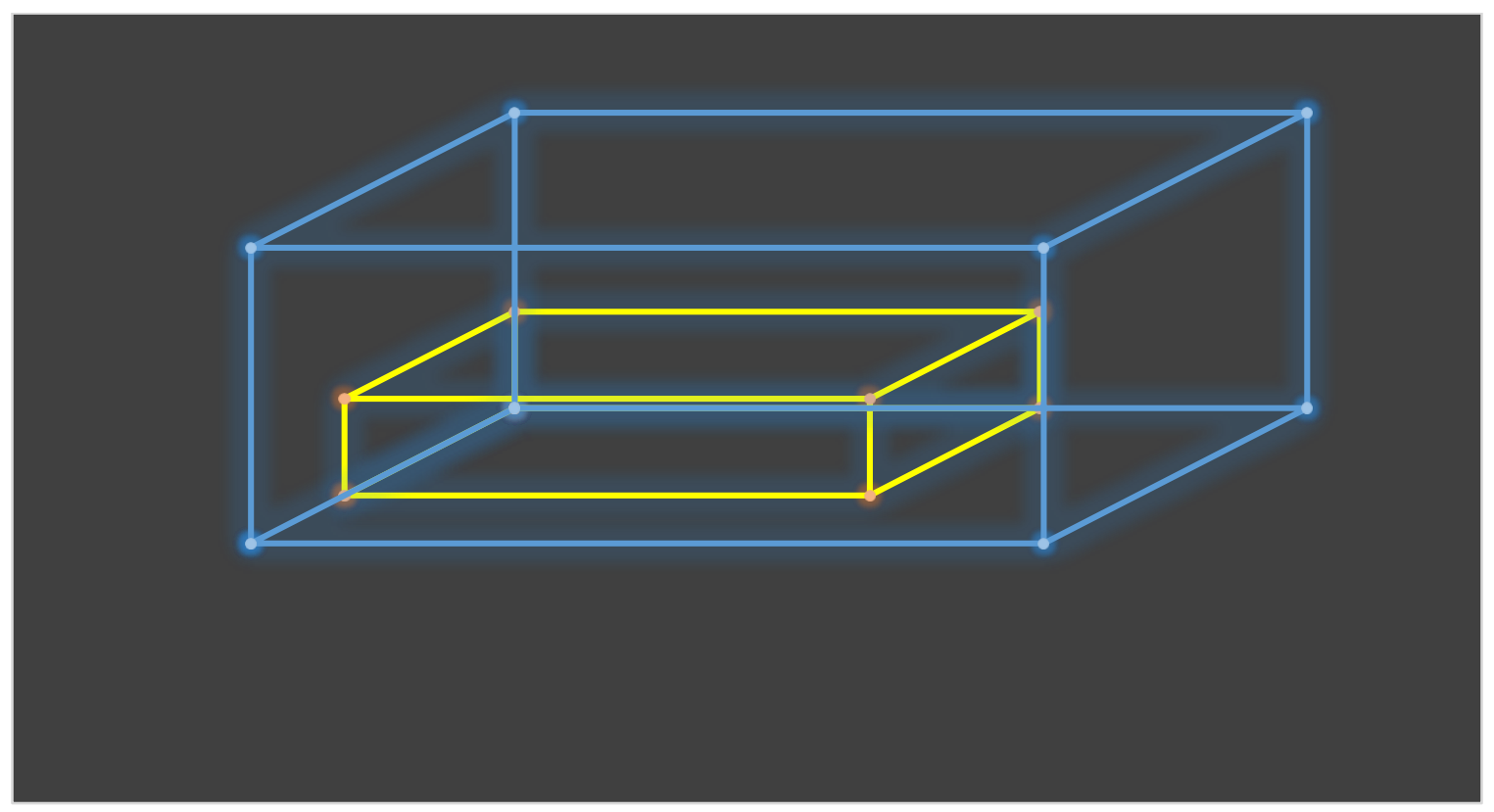

Fuente: Producción propia

Para el vector de infraestructura el paralelepípedo de mayor y menor volumen son el Portal 80 y Centro Mayor, representados por el amarillo y azul respectivamente. Basado en los datos, Centro Mayor tiene 166.309 m2 más que Portal 80, siendo casi el tripe de tamaña de este, pero la diferencia de variedad no se ve tan marcada, que permite reiterar el hecho de que el tamaño no es una variable significativa, depende más el 
aprovechamiento del espacio, y se puede ver de manera clara que aquí no se presenta la convergencia estratégica por parte de Centro Mayor, ya que a pesar de no diferenciarse a gran escala la variedad, si lo logra con la experiencia, que puede ser causa del valor agregado que ofrece dentro de sus lugares de esparcimiento, no solo enfocándose en la parte comercial, si no también en otros servicios como lo puede ser la cultura, la educación o la salud.

Pero para entenderlo de una manera más profunda, no solo se analizará cómo funciona cada centro comercial si no también, como funcionan dentro de su entorno, para ello se analizara cada fuerza de Porter y de esta manera entender de mejor manera como funciona este sector.

\subsection{Fuerzas de Porter}

\subsubsection{Analisis de las Fuerzas de Porter Para el sector de los Centros Comerciale de Bogotá}

El objetivo de este analisis, es relacionar los 12 centros comerciales que se estudian en esta investigación, con el fin de determinar que tanto impacta cada una de las fuerzas en este sector, que permite emprender acciones ofensivas y correctivas basado en los resultados obtenidos.

Las cinco fuerzas competitivas son : Nivel de rivalidad entre competidores existentes, poder de negociación de compradores, riesgo de ingreso, poder de negociación de proveedores y bienes sustitutos. 


\subsubsection{Nivel de rivalidad entre competidores existentes}

La rivalidad entre los competidores existentes tiene como objetivo una lucha por

aumentar la participación en el mercado, utilizando diferentes estrategias para ello, como

la competencia en precios, servicio al cliente, publicidad, ubicación, etc.

Tabla 3. Nivel de rivalidad entre competidores existentes

1 Nivel de concentración
2 Nivel de costos fijos
3 Velocidad de crecimiento del sector
4 Costos de Cambio
5 Grado de hacinamiento
6 Incrementos en la capacidad
7 Presencia Extranjera
8 Nivel de Barreras de Salida
$\quad$ a. Activos Especializados
b. Costos Fijos de Salida
c. Inter-relaciones Estratégicas
d. Barreras Emocionales
e. Restricciones Sociales - Gubernamentales

\begin{tabular}{|l|c|c|c|c|c|}
\hline Alto & Medio Alto & Equilibrio & Medio Bajo & Bajo & Inexistente \\
\hline & & $\mathbf{x}$ & & & \\
\hline & $\mathbf{x}$ & & & & \\
\hline & $\mathbf{x}$ & & & & \\
\hline & & & & $\mathbf{x}$ & \\
\hline & & $\mathbf{x}$ & & & \\
\hline & & & $\mathbf{x}$ & & \\
\hline & & & & $\mathbf{x}$ & \\
\hline & & & & & \\
\hline & $\mathbf{x}$ & & & & \\
\hline $\mathbf{x}$ & & & & & \\
\hline $\mathbf{x}$ & & & & & \\
\hline & $\mathbf{x}$ & & & & \\
\hline & & $\mathbf{x}$ & & & \\
\hline & & $\mathbf{x}$ & & & \\
\hline
\end{tabular}

EVALUACION FINAL NIVEL DE RIVALIDAD ENTRE COMPETIDORES EXISTENTES EMPRFSA XVZ IIMTTANA

\begin{tabular}{|l|c|c|c|c|c|c|}
\cline { 2 - 7 } \multicolumn{1}{c|}{} & Alto & Medio Alto & Equilibrio & Medio Bajo & Bajo & Inexistente \\
\hline $\mathrm{N}$ & 0 & 3 & 2 & 1 & 2 & 0 \\
\hline$\%$ & $0,0 \%$ & $37,5 \%$ & $25,0 \%$ & $12,5 \%$ & $25,0 \%$ & $0,0 \%$ \\
\hline
\end{tabular}

\section{Fuente. Producción propia.}

Actualmente el crecimiento del mercado es significativo. Según la asociación de centros comerciales (Acecolombia) en el 2019 se tiene proyectado la apertura de 24 nuevos centros de compras a nivel nacional. Esto agregara cerca de 565 mil metros cuadraros en 16 ciudades de Colombia. A nivel Bogotá a comienzos del año realizo la apertura de un 
nuevo centro comercial llamado Plaza Claro, con un complejo inmobiliario de 35.000 metros cuadrados de área comercial y 80.000 metros cuadrados de oficinas, y se tiene proyectado para el 2020-2021 abrir otra parte del centro comercial que está en proceso de construcción.

Por lo anterior, se puede determinar que el crecimiento del sector no es lento, por lo que la competencia es débil ya que las empresas pueden mejorar sus resultados con solo mantener su cuota de mercado

Para los centros comerciales esta representa una gran barrera, ya que es cada vez más difícil la rentabilidad por los arriendos millonarios, gastos de administración excesivos incluso con porcentajes de venta en algunos casos, los costos de servicios públicos para estratos comerciales, el costo de la nómina, los costos financieros con las entidades bancarias y obviamente los impuestos, han hecho que la rentabilidad se reduzca al mínimo y que la presión por el cumplimiento de una venta mínima para sostener la infraestructura, dañen la implementación de verdaderas estrategias comerciales (VOOJOO, 2019).

La desaceleración de la economía y los altos costos en los arriendos de locales también les pasan una costosa factura a los centros comerciales. En el primer caso, la menor dinámica de la economía se refleja en el descenso de las ventas por factores como el aumento en el IVA desde 2017 y la caída de la confianza, que llevó a muchos colombianos a contenerse o retrasar sus compras. Por otra parte, están los altos costos de los locales desde las épocas de bonanza económica, que apenas han comenzado a 
renegociar. Esto motivó la salida de muchas marcas debido a que las ventas no compensaban el gasto en arriendos.

Con esto se entiende, según Jorge E. Pereira (2012) productos que tienen valor económico y se distinguen en términos de atributos, pero para la perspectiva del mercado o de los consumidores, termina convirtiéndose en un "commodity". Esto se puede ver en los centros comerciales como lo son los espacios gastronómicos, la conciencia ambiental y cultura (Piñeros, 2018). La cifra cobra importancia, si se tiene en cuenta que son lugares que trascienden las ventas de productos y servicios, y que también incluyen aspectos de arquitectura sostenible, como la adecuación de fachadas amigables con el medioambiente, hasta locaciones diseñadas para sobresalir más allá de los productos que ofrecen.

Según la Cámara Colombiana de la Construcción (Camacol), al aspecto comercial hay que agregarle lugares de reunión y de esparcimiento, que, además, tienen un impacto económico, muy ligado cuando se trata de medir la confianza de los consumidores. (Piñeros, 2018) El nivel de hacinamiento en el sector de los centros comerciales está en un nivel medio bajo, como se puede ver en la tabla 3, ya que el nivel de concentración se encuentra en equilibrio, y como se mencionó anteriormente cuando el sector está en crecimiento, la estrategia principal es concentrar a su público objetivo y así evitar el isomorfismo y el hacinamiento. 


\subsubsection{Poder de negociación de los compradores}

El grado de concentración se encuentra en equilibrio, esto debido a que en los últimos años los centros comerciales han estado innovando en los servicios ofrecidos para motivar a las familias a visitar con más frecuencias los centros comerciales, donde se pudo evidenciar que la fortaleza principal ya no es la venta de vestuario y calzado, si no los otros servicios que puede llegar a ofrecer cada uno de ellos, permitiendo así aumentar un punto porcentual anualmente, manteniendo sus ingresos.

\section{Tabla 4. Poder de Negociación de compradores}

\begin{tabular}{|c|c|c|c|c|c|c|c|}
\hline \multirow{2}{*}{1 Grado de concentración } & & \multirow[t]{2}{*}{ Alto } & \multicolumn{3}{|c|}{\begin{tabular}{|l|l|l|} 
Medio Alto & Equilibrio & Medio Bajo \\
\end{tabular}} & Bajo & Inexistente \\
\hline & & & & $\bar{x}$ & & & \\
\hline 2 Importancia del proveedor para el comprador & & & & $x$ & & & \\
\hline 3 Grado de hacinamiento & & & & & $\mathbf{x}$ & & \\
\hline 4 Costos de cambio & & & & & $\mathbf{x}$ & & \\
\hline 5 Facilidad de Integración hacia atrás & & & & & & $x$ & \\
\hline 6 Información del comprador sobre el proveedor & & & & & & $\mathbf{x}$ & \\
\hline 7 Los compradores devengan bajos márgenes & & & & & & $\mathbf{x}$ & \\
\hline 8 Grado de Importancia del Insumo & & & & & $\mathbf{x}$ & & \\
\hline EVALUACION FINAL & & Alto & Medio Alto & Equilibrio & Medio Bajo & Bajo & Inexistente \\
\hline PODER DE NEGOCLACION DE COMPRADORES & $\mathbf{N}$ & $\mathbf{0}$ & 0 & 2 & 3 & 3 & 0 \\
\hline EMPRESA XYZ LIMITADA & $\%$ & $0,0 \%$ & $0,0 \%$ & $25,0 \%$ & $37,5 \%$ & $37,5 \%$ & $0,0 \%$ \\
\hline \multicolumn{8}{|l|}{ Fuente. Producción propia } \\
\hline \multicolumn{8}{|c|}{ Más allá del impacto que puede ejercer la economía local, la integración de tecnologías, la } \\
\hline \multicolumn{8}{|c|}{ globalización y otros elementos que por naturaleza marcan la tendencia en el sector retail. } \\
\hline Es importante considerar la importanc & s pr & edore & para ce & ontrib & uir sust & tancia & Imente \\
\hline
\end{tabular}


A nivel de los consumidores, el hacinamiento es muy bajo como se ve en la tabla 4, ya que la proporción de cantidad de centros comerciales es mucho menor al nivel de número de la población. En la actualidad se tiene 45.5 millones de habitantes (DANE, 2018), con un promedio de 70 centros comerciales, que cuentan con 2.158.000 metros cuadraros en total. (El Nuevo Siglo, 2016), lo que representaría $0.047 \mathrm{~m} 2$ por habitante.

Para los consumidores es muy fácil cambiar de centro comercial, ya que la mayoría ofrece casi los mismos servicios, ahí es donde se debe generar una estrategia por parte de las empresas para atraer y mantener los consumidores, como son los servicios adicionales que ofrecen, como lo son los gimnasios, salas de cine, tiendas de cadena, entre otros.

En materia de inversiones, los 8 centros comerciales inaugurados este año habían requerido recursos por 680 millones de dólares, de acuerdo con Acecolombia. Para el próximo año la dinámica sigue adelante, pues está previsto inaugurar 13 centros comerciales más en el país con una inversión superior a la de 2018.

\subsubsection{Riesgo de ingreso}

En materia de innovación, buena parte de los centros comerciales actualmente en obra incorporan las tendencias internacionales que buscan que los visitantes encuentren experiencias que los inviten a disfrutar y, por supuesto, a consumir. El riesgo de igual manera de ingreso de nuevos competidores es baja, ya que el nivel de inversión y como se mencionó anteriormente de innovación son muy altos, actualmente los que están en proceso de ingresar a este mercado en la ciudad de Bogotá, son de Centroamérica y de inversión extranjera como lo es el nuevo centro comercial Muliplaza construido por el Grupo Roble, uno de los gigantes de la construcción en América Látina. 
Por eso, busca enfrentar los nuevos desafíos con inversión, innovación y presencia de competidores internacionales, entre sus frentes más dinámicos. El gran desafío está en los costos de arrendamiento de los locales, que han motivado a algunos comerciantes a pedir renegociarlos o, incluso, a retirarse.

Tabla 5. Riesgo de ingreso

RIESGO DE INGRESO

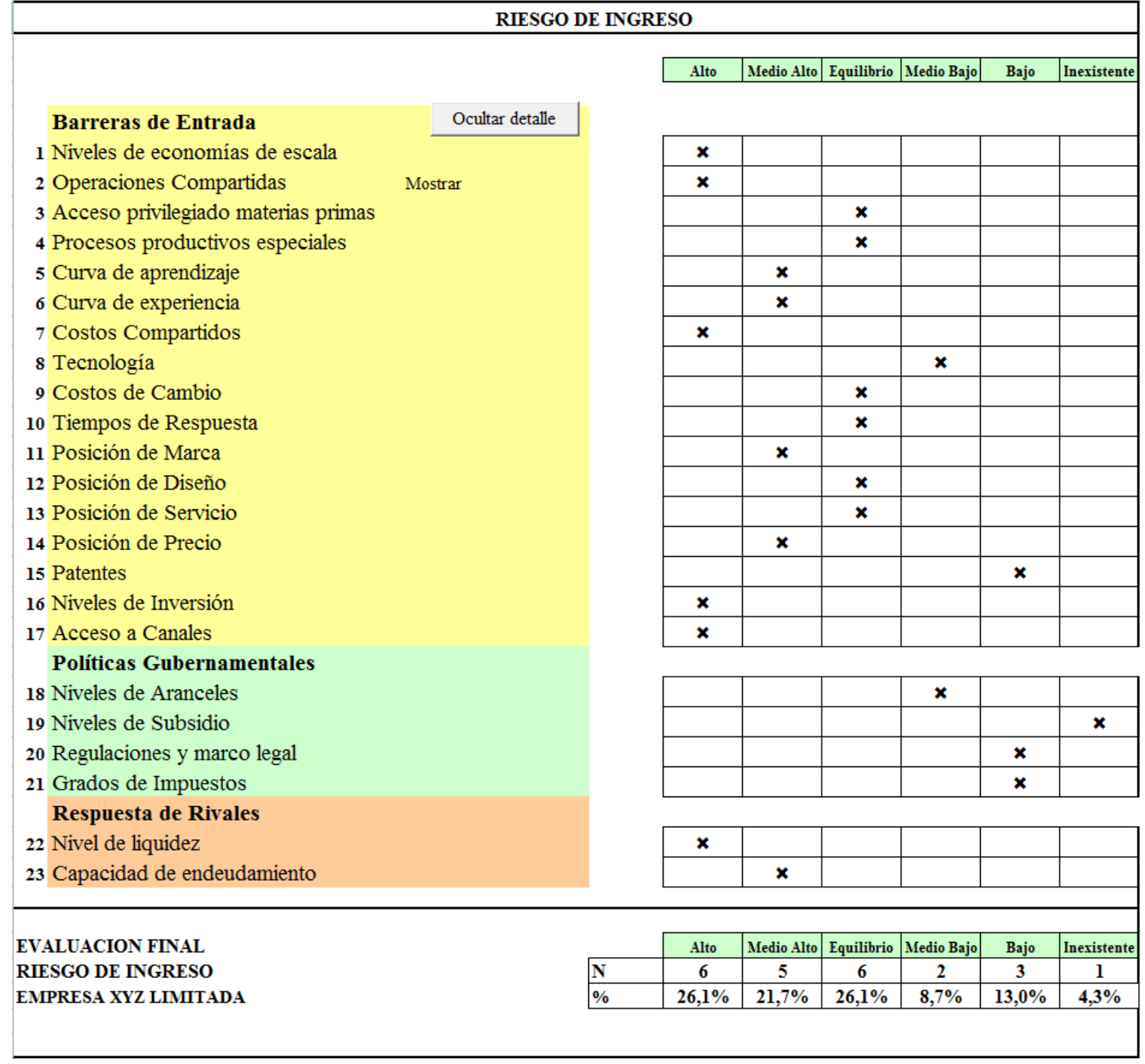

Fuente. Producción propia

\subsubsection{Poder de negociación de los proveedores.}


El 94\% de las compras del sector se hacen a proveedores nacionales. Sólo 6\% de las compras es importado. El $85 \%$ de sus proveedores son pequeñas y medianas empresas. Con el uso de tecnologías de conectividad y cooperación con los proveedores han logrado integrarse con $80 \%$ de sus proveedores bajo el sistema EDI, y hacer por este medio $90 \%$ de las compras. (Osorio, 2015).

Existe muy poco amenaza de integración hacia adelante por parte de los proveedores, ya que Colombia se encuentra en una economía de escala, tanto proveedores y centros comerciales salen ganando, y con la economía creciendo, permite que el consumo por parte de la población aumente.

\section{Tabla 6. Poder de negociación de proveedores}

\begin{tabular}{|c|c|c|c|c|c|c|c|}
\hline & & Alto & Medio Alto & Equilibrio & Medio Bajo & Bajo & Inexistente \\
\hline 1 Grado de concentración & & & $\mathbf{x}$ & & & & \\
\hline 2 Presión de sustitutos & & & & $\mathbf{x}$ & & & \\
\hline 3 Nivel de ventaja & & & & & $\mathbf{x}$ & & \\
\hline 4 Nivel de importancia del insumo en procesos & & & & & $\mathbf{x}$ & & \\
\hline 5 Costos de cambio & & & & & $\mathbf{x}$ & & \\
\hline 6 Amenaza de integración hacia delante & & & & & $\mathbf{x}$ & & \\
\hline 7 Información del proveedor sobre el comprador & & & & & $\mathbf{x}$ & & \\
\hline \multirow{2}{*}{8 Grado de hacinamiento } & & & & & & $\mathbf{x}$ & \\
\hline & & & & & & $\mathbf{x}$ & \\
\hline EVALUACION FINAL & & Alto & Medio Alto & Equilibrio & Medio Bajo & Bajo & Inexistente \\
\hline PODER DE NEGOCIACIÓN DE PROVEEDORES & $\mathbf{N}$ & $\mathbf{0}$ & 1 & 1 & 5 & 2 & $\mathbf{0}$ \\
\hline EMPRESA XYZ LIMITADA & $\%$ & $0,0 \%$ & $11,1 \%$ & $11,1 \%$ & $55,6 \%$ & $22,2 \%$ & $0,0 \%$ \\
\hline
\end{tabular}

Fuente. Producción propia

\subsubsection{Bienes sustitutos.}

Ubicación, variedad, comodidad y calidad, son algunos de los valores agregados que ofrecen el sector. Sin embargo, la disminución de tiempo disponible de las personas, los 
problemas de inseguridad, entre otros pueden abrir nuevas áreas de oportunidad para atender a las personas que no tienen tiempo para ir a hacer sus compras. Para estos consumidores, las tiendas virtuales pueden ser una alternativa interesante, así como los pedidos telefónicos y servicios a domicilio. Igualmente los almacenes con horarios extendidos o 24 horas del día. Una tienda virtual no requiere tener físicamente los productos en exhibición y, por lo tanto, tampoco requiere mantener existencias en múltiples tiendas. Sólo necesita un almacén donde pueda surtir los pedidos que los clientes van solicitando. Los ahorros en infraestructura e instalaciones, así como la reducción en personal, con un sistema de entrega eficiente pueden transformarse en una ventaja de las tiendas virtuales. Por tal motivo las grandes cadenas cuentan con una página web que hace las veces de tienda virtual con el fin de ocupar este espacio antes de que la competencia se adelante (Osorio, 2015). También se tiene la ayuda de nuevas aplicaciones que permite a los consumidores comprar en la comodidad de su casa, desde un helado, hasta un sofá o un televisor, como lo son Rappi, merqueo, Domicilios.com, Uber eats, entre otros.

Finalmente con la información recolectada, se realizo una tabulación de las cinco fuerzas de Porter, como se ve en la tabla 3, los factores que afectan a las fuerzas de Porter esta debajo del punto de equilibrio, mostrando el $28,8 \%$ en medio bajo, lo que significa que las amenazas de los factores externos hacia los centros comerciales es muy poca. Basado en lo anterior, la baja amenaza se debe principalmente, hablando en términos económicos, a la inyección de capital que se tiene que tener para llegar a lograr ese posicionamiento en el mercado, y también cabe destacar, no solo la inversión para crear infraestructura, estudiar el mercado, y captar al público, sino también la generación de 
nuevas ideas para salir de la convergencia estrategica, y el consumidor no logre visualizar un valor agregado a lo que quieran ofrecer y no se logre de esa manera el público y los ingresos esperados, por lo que se debe generar un diferenciador, donde permita que los consumidores lo prefieran sin importar la zona geográfica en la que se encuentre.

Tabla 3. Resumen de todos los factores de las fuerzas de Porter

\begin{tabular}{|l|c|c|c|c|c|c|}
\cline { 2 - 7 } \multicolumn{1}{c|}{} & Alto & Medio Alto & Equilibrio & Medio Bajo & Bajo & Inexistente \\
\hline $\mathbf{N}$ & 6 & 13 & 7 & 15 & 10 & 1 \\
\hline$\%$ & $11,5 \%$ & $25,0 \%$ & $13,5 \%$ & $28,8 \%$ & $19,2 \%$ & $1,9 \%$ \\
\hline
\end{tabular}

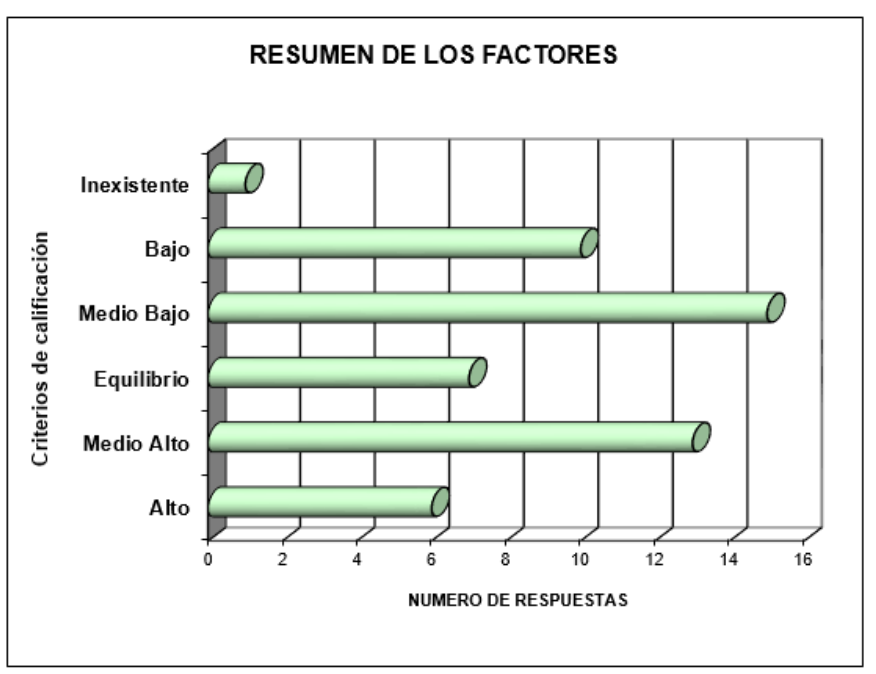

Fuente. Producción propia

Actualmente, lo que tiene más amenazado a los centros comerciales, son los bienes sustitutos, siendo la tecnología el factor determinante, esto a causa de las preferencias de los consumidores. Una ciudad como Bogotá, las personas están en constante movimiento y les queda muy poco tiempo para dedicarlo al ocio, y una de sus alternativas es el uso de aplicaciones, para que todo sea más rápido y llegue hasta la puerta de su casa, por esto, muy pocos centros comerciales están en esa vanguardia, para poder mantenerse e innovando al mismo tiempo, como estrategia es estar al día con lo más alto en tecnología. 
Como se logra analizar en la tabla 4 , la siguiente amenaza es el riesgo de ingreso, como se mencionó antes la apertura de nuevos centros comerciales se ve reflejado, como lo es con el centro comercial Multiplaza y el que esta pronto a inaugurar El Edén, esto presenta sus pros y sus contras. Con la llegada de nuevos centros comerciales, los anteriores competidores deben estar preparados y de esta manera puedan aprovechar para inyectar más capital para la innovación y nuevos espacios para los consumidores, y darle apertura a nuevas opciones, como lo es el medio ambiente y la cultura, permitiendo no solo estar a la vanguardia sino también estar encima de sus competidores antiguos y los que están ingresando, con una ventaja extraordinaria en la curva de aprendizaje.

Si un nuevo inversor decide ingresar en el sector, corre muchos riesgos, ya que no cuenta con la ventaja de los competidores antiguos, como lo son los acuerdos con los proveedores, el manejo del mercado, la captación de los consumidores y el posicionamiento que ha generado en los años en el mercado, pero para ambos, antiguos como nuevos, las utilidades de la operación son elevadas, ya que el flujo de gente es constante, donde va conectado al consumismo.

Como lo menciona Nattermann (1997) que estudió el fenómeno del hacinamiento y la erosión de los beneficios financieros de un sector estratégico, los centros comerciales muestra una fuerza muy grande en las barreras de entrada como las economías de escala, dejando en desventaja a los que tratan de ingresar al sector, las operaciones y los costos compartidos, las curvas de aprendizaje y experiencia, la sofisticación tecnológica, los recursos inimitables, el equilibrio económico de la oferta y la demanda y las maniobras estratégicas, entre otros. 
Tabla 4. Intensidad Fuerzas de Mercado

\begin{tabular}{lr}
\hline NIVEL DE RIVALIDAD ENTRE COMPETIDORES EXISTENTES & $\mathbf{2 , 7 5}$ \\
PODER DE NEGOCIACION DE COMPRADORES & $\mathbf{1 , 8 8}$ \\
RIESGO DE INGRESO & $\mathbf{3 , 2 6}$ \\
PODER DE NEGOCIACIÓN DE PROVEEDORES & $\mathbf{2 , 1 1}$ \\
BIENES SUSTITUTOS & $\mathbf{3 , 0 0}$
\end{tabular}

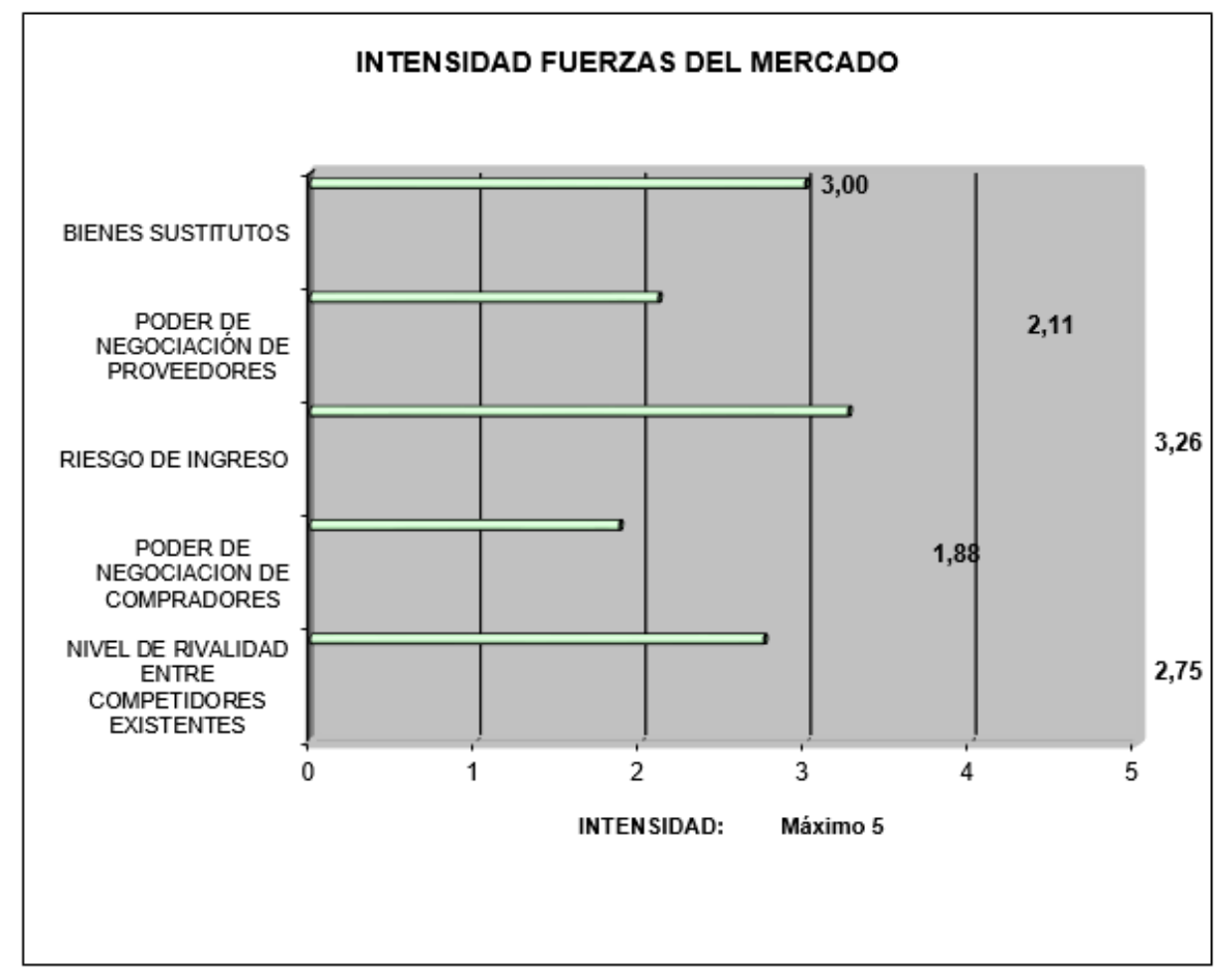

Fuente. Producción propia

En este tipo de mercado se presenta mucho la convergencia estratégica donde la competencia por los clientes genera reflexiones estratégicas similares. Los modelos mentales construidos a largo de los años por las empresas se han hecho tan parecidos, que las respuestas que dan los rivales del sector se parecen cada vez más. 
Tabla 5. Atractividad por barreras de entrada y salida

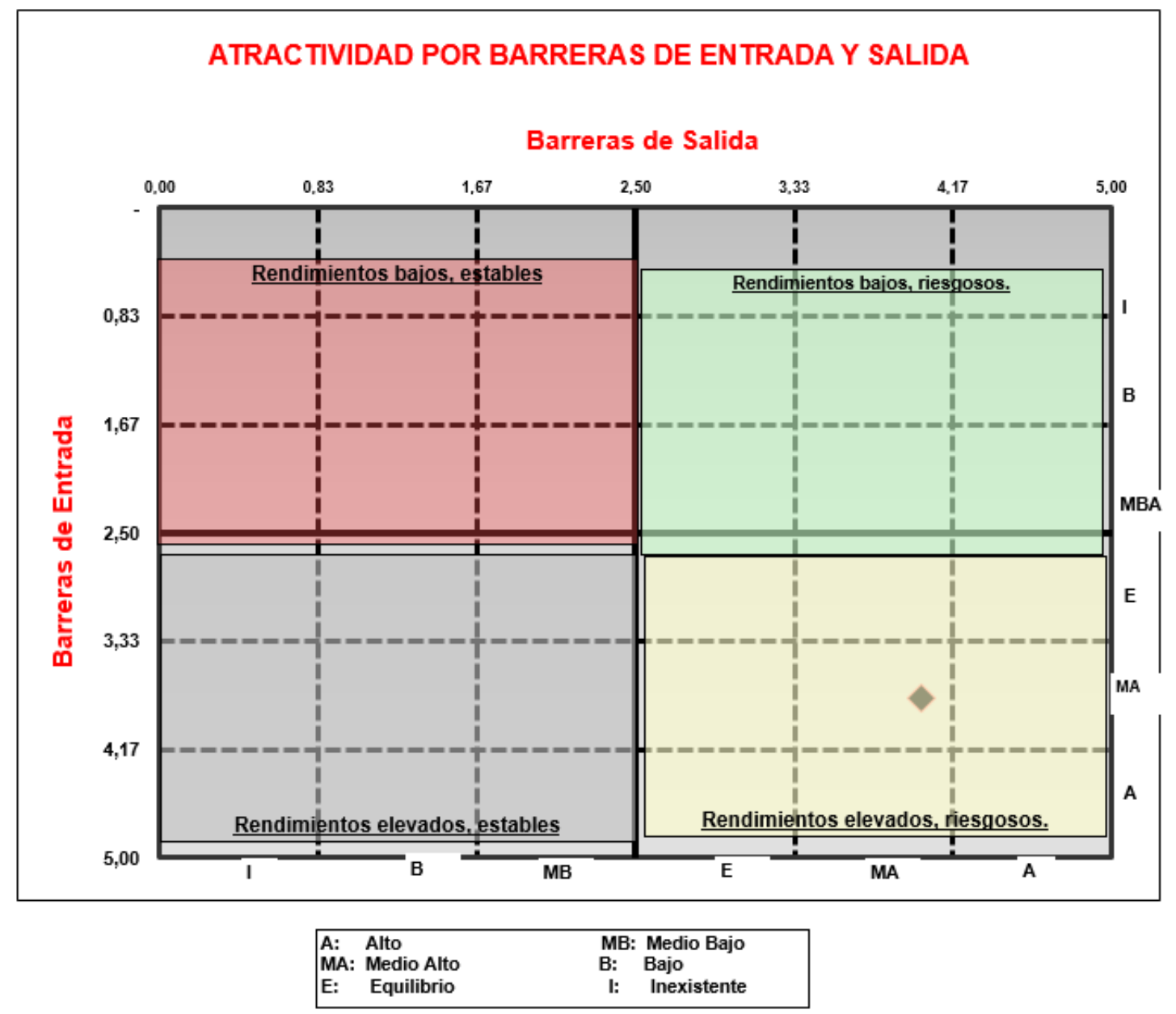

Figura3. Producción propia

La amenaza de entrada de nuevos rivales al sector depende de la presencia de barreras de entrada y del tipo de reacción de los competidores ya existentes en el mercado. Para los centros comerciales las barreras son altas en este sector, lo que lleva una reacción agresiva de los que están actualmente en el mercado.

Por lo anterior, se puede decir que con barreras de entrada tan fuertes en el sector de los centros comerciales, el ingreso de nuevos competidores es muy baja, pero como lo muestra 
la Tabla 6 , si los nuevos competidores tienen la capacidad de invertir y pueden manejar los costos de cambio, procesos productivos especiales, acceso privilegiado de materias primas y las nuevas tecnologías, podría ser una gran amenaza para los competidores existentes.

\section{Tabla 6. Barreras de entrada}

GRADO DE ATRACTIVIDAD

CALCULO DE BARRERAS DE ENTRADA

\begin{tabular}{|c|c|c|c|c|c|c|}
\hline \multirow[b]{2}{*}{ Barreras de Entrada } & Alto & Medio Alto & Equilibrio & Medio Bajo & Bajo & Inexistente \\
\hline & & & & & & \\
\hline Niveles de economías de escala & $x$ & & & & & \\
\hline Operaciones Compartidas & $x$ & & & & & \\
\hline Acceso privilegiado materias primas & & & $x$ & & & \\
\hline Procesos productivos especiales & & & $x$ & & & \\
\hline Curva de aprendizaje & & $x$ & & & & \\
\hline 6 Curva de experiencia & & $\mathbf{x}$ & & & & \\
\hline 7 Costos Compartidos & $\mathbf{x}$ & & & & & \\
\hline Tecnología & & & & $\mathbf{x}$ & & \\
\hline Costos de Cambio & & & $\mathbf{x}$ & & & \\
\hline Tiempos de Respuesta & & $x$ & & & & \\
\hline Posición de Marca & & $x$ & & & & \\
\hline Posición de Diseño & & $\mathbf{x}$ & & & & \\
\hline Posición de Servicio & & $\mathbf{x}$ & & & & \\
\hline Posición de Precio & & $x$ & & & & \\
\hline Patentes & & & & & $x$ & \\
\hline 6 Niveles de Inversión & $x$ & & & & & \\
\hline 7 Acceso a Canales & & $\mathbf{x}$ & & & & \\
\hline
\end{tabular}

Tamaño Barreras de Entrada

\section{Fuente. Producción propia}

Cuando se habla de barreras de entrada, también de habla de salida, para un sector como

lo es el de los centros comerciales, es muy difícil salir del mercado, es más factible generar estrategias para mantenerse en el mercado mientras pasa la tormenta, esto es debido a que el capital tanto de recursos humanos y económicos son muy elevados, como tienen activos especializados y manejan todo tipo de servicios, salir del mercado no solo 
implica dejar de ofrecer servicios, si no también afectar la economía del sector, entrando en un proceso de liquidación lo que podría tardar meses hasta años.

\section{Tabla 7. Barreras de salida}

GRADO DE ATRACTIVIDAD

TAMAÑO BARRERAS DE SALIDA

\begin{tabular}{|l|c|c|c|c|c|c|c|}
\hline & Alto & Medio Alto & Equilibrio & Medio Bajo & Bajo & Inexistente \\
\hline Barreras de Salida & \multicolumn{1}{l|}{} \\
\hline & $\mathbf{x}$ & & & & & \\
\hline a. Activos Especializados & $\mathbf{x}$ & & & & & \\
\hline b. Costos Fijos de Salida & & $\mathbf{x}$ & & & & \\
\hline c. Inter-relaciones Estratégicas & & & $\mathbf{x}$ & & & \\
\hline d. Barreras Emocionales & & & $\mathbf{x}$ & & & \\
\hline e. Restricciones Sociales - Gubernamentales & & & & \\
\hline
\end{tabular}

Tamaño Barreras de Salida

Fuente. Producción propia

Una de las barreras de salida más importantes son los costes fijos como los pagos por indemnización a empleados o proveedores propios de la finalización de un proyecto o negocio. Es muy frecuente que estas barreras y otras similares fuercen a los centros comerciales continuar funcionando a pesar de sus malos resultados evitando su salida, También, las restricciones sociales y gubernamentales ejercen algunos grupos de interés, que puede causar huelgas o manifestaciones por parte de la nómina. Respecto al aspecto político, la legislación o la presión política pueden ser una importante barrera de salida. En definitiva, la posesión de activos difíciles de liquidar, la alta regulación en el ámbito laboral y sus correspondientes costes para este sector o los compromisos personales y emocionales con socios o empleados son algunas de estas barreras, muy repetidas a lo 
largo de la historia empresarial. En algunos casos, se ve reflejado el orgullo o el daño a la imagen los que evitan una salida aun siendo necesaria.

\section{Conclusiones.}

La tendencia al Isomorfismo en el subsector de los centros comerciales, se presenta de manera significativa, siendo este el principal factor que reduce la competitividad, para poder evitar el asentamiento y la convergencia estratégica, los centros comerciales deben implementar estrategias de innovación empresarial y sectorial, ya que el isomorfismo provoca convergencia e imitación.

Con el nuevo dinamismo del mercado, este subsector, debe estar en constante cambio, presentando mayor ventaja los centros comerciales que han permanecido más tiempo en el mercado, aprovechando sus recursos, como los son, la curva de aprendizaje, el trato con los proveedores, y los consumidores, entre otros. Por otro lado, los que están ingresando en este mercado deben inyectar una gran cantidad de capital, incluyendo también la innovación y debe estar de la mano con las nuevas tendencias hacia los consumidores.

La entrada al mercado de nuevos competidores, lleva a los antiguos a centrar sus fuerzas estratégicas y de mercado en el sector, pero siempre manteniendo el foco en toda la población, esto con el fin de no perder la circulación de los consumidores en los centros comerciales. La rivalidad entre empresas

La rivalidad entre las empresas, se debe al posicionamiento del mercado, entre mejor se encuentre sobre sus pares, mayor va a ser la porción que tenga sobre este, utilizando 
diferentes tácticas como la disminución de precios, mejora o creación de productos, adquisiciones, etc.; situación que marca al interior de la empresa las necesidades de innovación para hacer frente a las estrategias de los competidores.

Para los consumidores la mayor prioridad y preferencias que tiene es la variedad que logre tener cada empresa, por eso a la hora de escoger un centro comercial, ese va a ser su mayor punto de referencia, y este debe ir ligado a las experiencias, la mayoría de los centros comerciales estudiados en la investigación se centran principalmente en la infraestructura y variedad, pero como ya se mencionó antes el tamaño no es lo que importa si no las experiencias que se logren tener.

Por consiguiente, para que los centros comerciales logren atraer y mantener mayor público, no solo debe centrarse en zonas comerciales, si no también en zonas de esparcimiento, ofreciendo otro tipo de servicios, como puedes ser zonas tematizadas, lugares de salud, eventos. Etc. Un impulsor para cerrar las brechas del mercado y aprovechar las manchas blancas que tienen los competidores o ellos mismos, como se ve en la matriz T, es el estudio y el análisis de la imitación, ya que esta fomenta la aceleración para el desarrollo de nuevos productos, incentivando la innovación. La imitación lleva a las empresas a quedarse en la zona de confort y evitar futuros riesgos financieros, pero al mismo tiempo genera que se estanque la empresa y da paso para que los competidores lo sobrepasen y coja la mayor parte del mercado, por eso es tan importante aplicar nuevas estrategias de negocio, donde permita que los consumidores los sigan prefiriendo. 
Para dar respuesta a la necesidad de supervivencia de las empresas y afrontar los diferentes fenómenos o enfermedades que deterioran los sectores e incrementan las tasas de mortalidad empresarial, se plantean tres elementos necesarios para favorecer la adaptación y el crecimiento empresariales, la primera es una capacidad transformada en actitud, conocida como la creatividad empresarial, la segunda es la forma de actuar para perseverar en el entorno, también llamada como innovación organizacional, y por último una estructura interna que involucre las dos anteriores, a esto se le denomina arquitectura organizativa innovadora.

Se les recomienda a los centros comerciales, es estar en constante contacto con el público, para poder ofrecer un amplio portafolio, satisfaciendo sus necesidades y superando sus expectativas, para ello tienen que tener claro los factores externos que deben enfrentar. También es importante aprovechar al máximo los espacios que cuenta cada centro comercial, así poder ofrecer mayor variedad a los consumidores y mejorando sus experiencias de compra al momento de ingresar al establecimiento, añadiendo un valor agregado sobre los otros.

En conclusión, la tendencia estratégica sectorial proponen acciones diferentes evitando la morbilidad del sector, la mayoría de centros comerciales se mantienen en constante cambio, como lo son en la infraestructura como lo hizo Gran Estación y Plaza de las américas, u ofrecimiento de otros servicios, como spas, iglesias, teatros, entre otros. Esos factores diferenciales permiten que el mercado este en constante cambio y el Isomorfismo se evite. 


\section{Referencias}

Archila Saa, H., Figueroa Garcia, L., Leal Vergara, C., Ortega Torres, F., \& Rivera Rodriguez, H. (2011). Turbulencia empresarial en Colombia: el caso del sector cementero. Bogotá: Editorial Universidad del Rosario.

Audretsch, D. B. (1995). Innovation, growth and survival. International Journal of Industrial Organization, 441-457.

Caneda, M. C. (2010). Dirección Estratégica Innovadora. Coruña: Netbiblo, S.L.

Caneda, M. C. (2015). DIRECCIÓN ESTRATÉGICA DE LA EMPRESA. La coruña: IFFE Business School.

DiMaggio, P. J., \& Powell, W. W. (1983). The Iron Cage Revisited Institutional Isomorphism and Collective Racionality. American Sociological Review, 48(2), 147-160.

Dinero. (27 de 04 de 2016). Obtenido de https://www.dinero.com/empresas/articulo/ranking-de-los-centros-comercialesmas-poderosos-de-bogota/222918

El Nuevo Siglo. (24 de 05 de 2016). Obtenido de https://elnuevosiglo.com.co/articulos/52016-la-ciudad-de-los-centros-comerciales

Galbraith, J. R. (1973). Designing complex organizations. Addison-Wesley Publishing Co.

ISOMORFISMO VS. EFICIENCIA EN EL ANÁLISIS ORGANIZACIONAL. (Enero de 1999). Empresa y Humanismo., págs. p137-144.

Johann Heinz Martínez Huartos, H. A. (2011). Adquisición de ventajas competitivas mediante la generación de un territorio estratégico. Mexico.

Karlins, J. N. (2008). El cuerpo habla. Editoria Sirio, S.A.

Marín-Idárraga, D. A. (oct-dic2013). La conformación del currículo en Administración: un estudio desde el isomorfismo institucional. Estudios Gerenciales, Vol. 29 Issue 129, p466-475. 10p.

Mintzberg, H. (s.f.). Planning on the left side and manging on the right. Harvard Business Review.

Nattermann, P. M. (s.f.). Competitor Behavior in response to new entry: The Case of the German mobile phone market 1986-1998. Competitor Behavior in response to new entry: The Case of the German mobile phone market 1986-1998.

Osorio, C. M. (2015). Analisis sectorial de las grandes superficies en Colombia. Santiago de Cali.

Pichère, P., Cadiat, A.-C., \& Serra, M. M. (2026). La pirámide de Maslow: Conozca las necesidades humanas para triunfar.

Piñeros, J. (27 de 07 de 2018). El Tiempo. Obtenido de https://www.eltiempo.com/economia/sectores/los-centros-comerciales-mas-allade-la-compraventa-de-productos-y-servicios-248724

Puerta, L. F. (2004). Interpretando a Porter. Bogota: Centro Editorial Universidad del Rosario. 
researchgate. (s.f.). Obtenido de https://www.researchgate.net/publication/319911401_CUANTIFICACION_DE_ LAS_NUEVAS_OPORTUNIDADES_DE_MERCADO_A_TRAVES_DE_UN_ PANORAMA_COMPETITIVO_TRIDIMENSIONAL

Rivera Rodriguez, H. (2010). CAMBIO ESTRATÉGICO PARA ENTORNOS

TURBULENTOS. Revista de la Facultad de Ciencias Económicas: Investigación y Reflexión., 87-117.

Rodriguez, H. A. (2004). El hacinamiento, la enfermedad que los estrategas deben curar. Rodriguez, H. A. (2004). El hacinamiento, la enfermedad que los estrategas deben curar.

Rodríguez, H. A., \& Puerta, L. F. (2008). Análisis estructural de sectores estratégicos. En H. A. Rodríguez, \& L. F. Puerta, Análisis estructural de sectores estratégicos (pág. 87). Colombia: Universidad del rosario.

Universida del Rosario. (2012). Obtenido de http://repository.urosario.edu.co/bitstream/handle/10336/4304/Anexo_1_Matriz_ T.pdf? sequence $=2$

VOOJOO. (12 de Junio de 2019). Obtenido de https://somosvoodoo.com/comercioelectrpnico/el-futuro-de-los-centros-comerciales-en-colombia/ 